\title{
Do Faults Preserve a Record of Seismic Slip: A second opinion
}

\author{
Christie D. Rowe ${ }^{\mathrm{a}}$, W. Ashley Griffith ${ }^{\mathrm{b}}$ \\ ${ }^{a}$ Department of Earth $\&$ Planetary Sciences, McGill University, 3450 University St., \\ Montréal, QC H3A 0E8, Canada \\ ${ }^{b}$ Department of Earth and Environmental Sciences, University of Texas at Arlington, \\ Box 19049, Arlington, TX, 76019, USA
}

\begin{abstract}
Exhumed fault zones offer insights into deformation processes associated with earthquakes in unparalleled spatial resolution; however it can be difficult to differentiate seismic slip from slow or aseismic slip based on evidence in the rock record. Fifteen years ago, Cowan $(1999)$ defined the attributes of earthquake slip that might be preserved in the rock record, and he identified pseudotachylyte as the only reliable indicator of past earthquakes found in ancient faults. This assertion was based on models of frictional heat production (Sibson, 1975, 1986) providing evidence for fast slip. Significant progress in fault rock studies has revealed a range of reaction products which can be used to detect frictional heating at peak temperatures less than the melt temperature of the rock. In addition, features formed under extreme transient stress conditions associated with the propagating tip of an earthquake rupture can now be recognized in the rock record, and are also uniquely seismic. Thus, pseudotachylyte is no longer the only indicator of fossilized earthquake ruptures.

We review the criteria for seismic slip defined by Cowan (1999), and we determine that they are too narrow. Fault slip at rates in the range $10^{-4}-10^{1} \mathrm{~m} / \mathrm{s}$ is almost certainly dynamic. This implies that features reproduced in experiments at rates as low as $10^{-4} \mathrm{~m} / \mathrm{s}$ may be indicators of seismic slip. We conclude with a summary of the rock record of seismic slip, and lay out the current challenges in the field of earthquake geology.
\end{abstract}

Keywords:

fault rocks, paleoseismology, pseudotachylyte, earthquakes, structural

Email address: christie.rowe@mcgill.ca (Christie D. Rowe) 
geology, mechanics of earthquakes

\section{Introduction}

The structural record of fault deformation is available everywhere faults are exposed - from surface scarps of active faults to exhumed shear zones extinct for millions of years. However, structural geologists' ability to read and understand the record of past deformation is incomplete. In order to interpret rheology or strain rates of past deformation, we rely on qualitative and quantitative comparisons to observable deformation where material properties and timescales are well-known. These are available from laboratory deformation experiments, where trade-offs between time, scale, temperature and material analogs allow for the formulation of constitutive relationships for material rheology, and the development of microstructures for qualitative comparison to the real world (e.g. Brace and Kohlstedt, 1980, Kirby, 1983 , Hirth et al., 2001). Seismic and geodetic studies provide information about slip rates and strain rates in actively deforming faults and shear zones, but do not elucidate deformation mechanisms at the scales which control fault strength in laboratory experiments, or in the lithosphere.

The dominant deformation mechanisms active at seismogenic depths, especially cataclasis, frictional sliding, and solution creep, still want for theoretical underpinnings. Although these have been reproduced in the laboratory, their behavior is highly sensitive to local conditions such as pore pressure, pore fluid chemistry, and stress state - all of which are difficult or impossible to constrain in ancient faults. How can we interpret past brittle deformation in the rock record?

Structural field and micro-scale observations can bridge the gap between the time-constrained models provided by experiments (at the cm-scale) and active deformation (at the 100s-1000s m-scale)(Sibson, 1977, 1989). Cowan (1999) approached this relationship by defining attributes that are characteristic of seismic slip. He defined an earthquake based on seismological constraints as a slip event that radiates seismic waves with periods of $10 s$ or less, has a seismic moment on order $\sim 10^{9}-10^{21} \mathrm{Nm}$, slip rates $\sim 0.1-1 \mathrm{~m} / \mathrm{s}$, rise time $\leq 5 \mathrm{~s}$, rupture velocity $\sim 2.5-3 \mathrm{~km} / \mathrm{s}$, and rupture durations $\leq 30 s$ and scaling with earthquake size. Based on that definition, Cowan (1999) challenged structural geologists to strictly determine which of these characteristics might contribute to preservation of evidence of earthquake in the rock record, and he concluded that only the rapid frictional heating which results in the formation of pseudotachylyte could be confidently 
identified as a 'fossilized earthquake'.

Significant progress has been made by integrating laboratory friction experiments with field observations in an attempt to re-create structures observed in fault gouge or cataclasite, and then relate these to the specific boundary conditions required to form them in the laboratory (e.g. Boutareaud et al., 2008, French et al., 2014, Rempe et al., 2014). Niemeijer et al. (2012) present a thorough review of this approach. In this contribution, we first revisit Cowan (1999)'s definition of an earthquake and argue for an expansion of the range of slip rates which are recognized as exclusively seismic. We review the progress made in pseudotachylyte research in the last 15 years, and then we summarize advances that have been made in defining other fault rock features which are diagnostic of fast slip, particularly through the identification of signatures of frictional heating. We explore preserved evidence of stress transients associated with dynamic rupture, as potential evidence of seismic slip. We conclude with a summary of current consensus on the evidence for past seismic slip in the rock record, and lay out the current challenges in the field of earthquake geology.

\section{Characteristics of Earthquakes}

Cowan (1999) defined earthquake rupture using a conceptual model based in fracture mechanics, where slip nucleates at one point and propagates along a two-dimensional discontinuity. The rupture velocity is the rate at which the front of the rupture moves along the fault, behind which particles adjacent to the fault accelerate such that the relative particle velocity (slip rate) across the fault increases from zero to a local peak velocity and then decays to zero at the tail end of the rupture (Figure 11A). As a result, the slip rate varies along the fault as a function of time and spatial position, but the average cumulative slip and slip velocity can be determined seismologically (Figure 1B). Cowan (1999) defined aseismic slip as slip which did not produce elastic waves detectible with short-period seismometers $(10 \mathrm{~s}$ or less). In practice, "aseismic slip" has come to mean fault slip at rates slower than earthquake slip, down to creep at tectonic plate rates; however, the exact cut-off may vary with detection capabilities.

It is a common assertion that the characteristic earthquake slip rate is on the order of $1 \mathrm{~m} / \mathrm{s}$ (e.g. Sibson, 1986). Although initially estimated by Brune (1976), this number is often attributed to Heaton (1990) who showed that the average slip rates on several large earthquakes was $\sim 0.8 \mathrm{~m} / \mathrm{s}$ and peak slip velocity at the rupture front could be $\sim 10-20 \mathrm{~m} / \mathrm{s}$. However, slip must persist at rates below $1 \mathrm{~m} / \mathrm{s}$ for significant periods of time after initial 


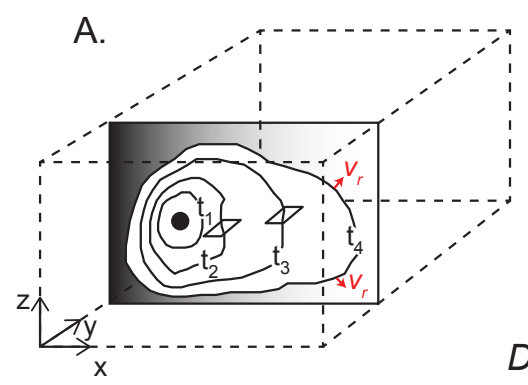

B.
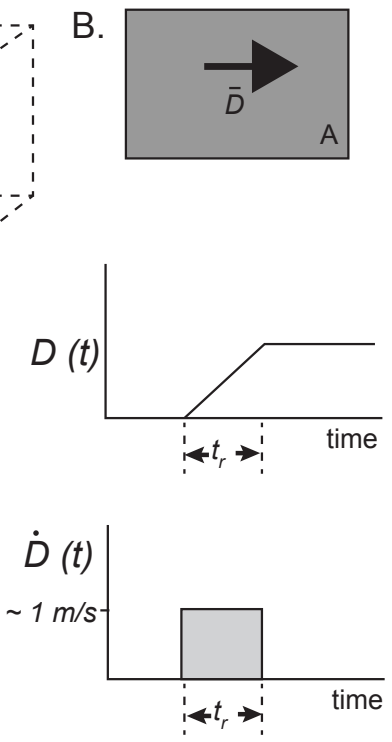

C.

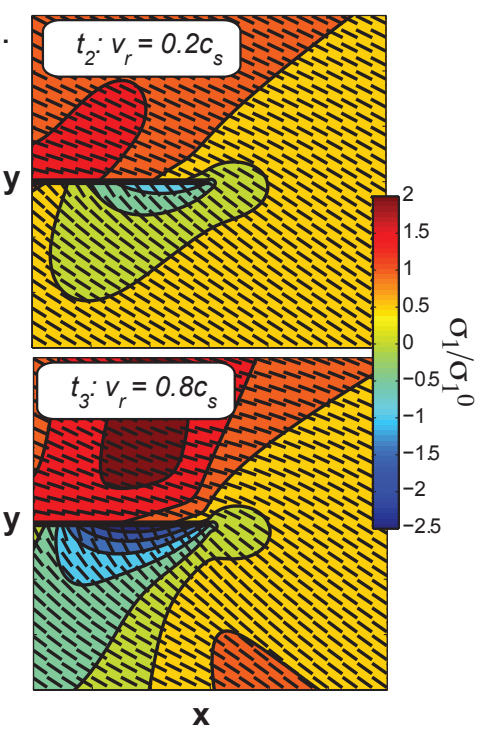

Figure 1: (a) Schematic illustration of a rupture propagating from hypocenter (filled circle) along a pre-existing fault contained within $x-z$ plane. Rupture front shown at successive times $t_{1}, t_{2}, t_{3}, t_{4}$, and boxes drawn at $t_{2}$ and $t_{3}$ rupture tip lines in x-y plane show locations of plots in c. Modified from Lay and Wallace (1995); Cowan (1999). (b) Idealized average dislocation model, where vector $D$ is the average slip and $A$ is the area of the rupture. The plot of $D(t)$ is the slip history at a point, and $t_{r}$ is the rise time. The plot of $D(t)$ is the slip rate, the time derivative of $\dot{D}(t)$. The shaded area under the boxcar curve is proportional to the seismic moment. Modified from Lay and Wallace (1995); Cowan (1999). (c) Schematic $\sigma_{1}$ fields (normalized by the static far field principal stress $\sigma_{1}^{0}$ ) at the tips of the rupture at times $t_{2}$ and $t_{3}$, respectively. Dashes show the directions of $\sigma_{1}$. The only difference between the two plots is the rupture velocity, $v_{r}$ shown as a function of the shear wave speed, $c_{s}$. Modified from Di Toro et al. (2005). 
peak slip rate (e.g. Dunham et al., 2011; Harris et al., 2011). Slip rate can also vary spatially along a fault, even during a single earthquake rupture (Beroza and Mikumo, 1996). Therefore, some areas of a rupture surface experience much higher or much lower average slip rates, and declining slip rate is likely to follow peak slip rate at a point.

The traditional end-member models of seismic $(\sim 1 \mathrm{~m} / \mathrm{s})$ vs. plate rate, aseismic $\left(\sim 10^{-10} \mathrm{~m} / \mathrm{s}\right)$ slip have been challenged by the recent discoveries of slip events at intermediate slip velocities (Rogers and Dragert, 2003 , Obara et al., 2004; Wallace and Beavan, 2006; Ito and Obara, 2006; Gomberg et al., 2008). These intermediate 'slow slip events' (SSE) are characterized by durations of days to months, and quasi-static slip which may be fast enough to emit low frequency seismic waves (c. $10^{-7}-10^{-8} \mathrm{~m} / \mathrm{s}$, Schwartz and Rokosky, 2007). Recent studies in Cascadia have shown that rupture propagation, not only slip rate, may be most important in controlling the generation of seismic tremor during slow slip events (Wech and Bartlow, 2014). Thus, rupture tip processes, not slip rate, may sometimes control whether deformation is seismologically detectable. Ide et al. (2007) and Peng and Gomberg (2010) used duration vs. moment plots to distinguish slow slip events from earthquakes, but neither duration nor moment is resolvable from the rock record of past fault slip. To facilitate comparison to field observations, we have replotted the events cataloged by Ide et al. (2007) in rupture velocity vs. slip velocity space (Fig. 2). It is clear that slip rates on the order of $10^{-4} \mathrm{~m} / \mathrm{s}$ are unique to earthquakes, as are rupture velocities greater than $\sim 10^{3} \mathrm{~m} / \mathrm{s}$. Traditional earthquakes are separated from slow slip events by over three orders of magnitude in rupture velocity and two to three orders of magnitude in slip rate (Figure 2). As earthquakes are clearly distinguished, the geological effects of fast slip and fast rupture constitute definitive evidence of past earthquakes. In our view, the " $1 \mathrm{~m} / \mathrm{s}$ criterion" is narrower than the range of exclusively seismic slip rates, and should no longer be used as a minimum bound for describing earthquake slip.

\section{Diagnostic criteria for fast slip}

\subsection{Clearly earthquake related: frictional heating}

By most estimates, around $90 \%$ of the total energy budget of earthquakes goes into work done overcoming frictional resistance, dwarfing other sinks such as surface energy, seismic wave radiation, and elastic strain energy (e.g. Scholz, 2002, and references therein). It stands to reason that such a significant portion of the energy budget should leave a trace in the rock 


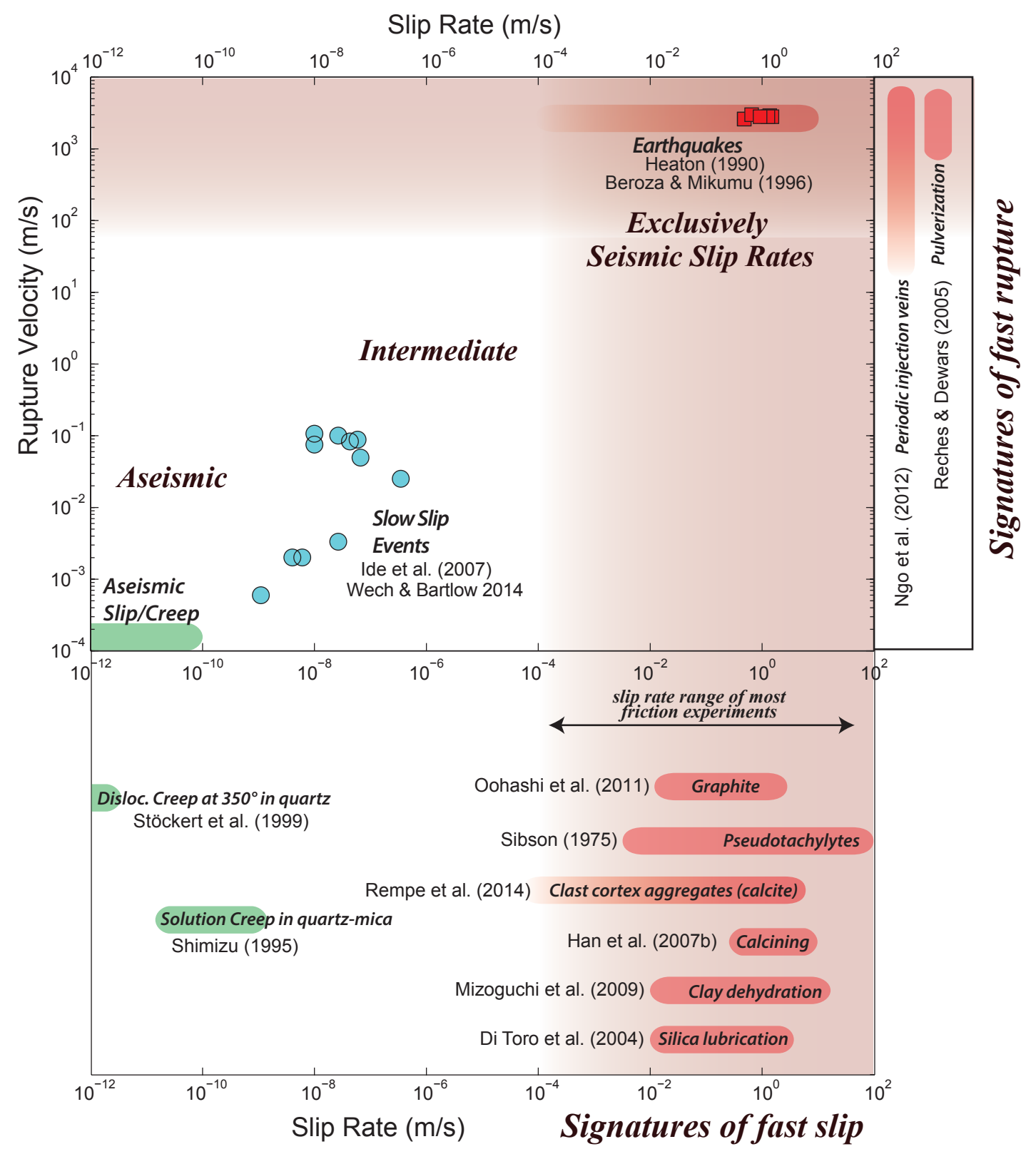

Figure 2: Slip rate and rupture propagation velocity for fast (seismic), intermediate (slow) and aseismic (creep) fault slip rates in active faults. Outside this plot, we show experimentally reproduced deformation mechanisms and their textural signatures, with constraints in either slip rate OR rupture velocity. 
record. Pseudotachylyte is linked to seismic slip when frictional heat production outpaces conductive dissipation (Sibson, 1973, 1975), raising temperatures on the fault surface to above the melting point of some or all mineral constituents of the fault rock. Thus, psudotachylyte has become a sort of holy grail for field geologists wishing to study seismic processes in the field (Sibson, 1973, 1975). Cowan (1999) cemented the paradigm that only pseudotachylyte provides incontrovertible evidence of past seismic slip in the rock record. Studies of pseudotachylyte-bearing faults have been increasingly leveraged to elucidate the details of coseismic stresses and source parameters. In addition, new methods have been developed for detecting frictional temperature increases whose peak is below the melting temperature of the fault rock, representing seismic frictional heating to a lower temperature than that which results in pseudotachylyte.

\subsubsection{Advances in pseudotachylyte studies}

Some authors prefer a field definition of "pseudotachylyte" to describe any aphanitic, dark colored fault rock (e.g. Wenk, 1978; Lin, 1996, 2008). Others use it to describe amorphous material formed during shear deformation (e.g. Pec et al. 2012b). Still others restrict the use of the term to solidified frictional melt, regardless of its appearance or subsequent overprinting (e.g. Kirkpatrick and Rowe, 2013). We take the latter position due to the utility of the energy constraints afforded by evidence of melt reactions.Although these various types of fault rocks might be difficult to distinguish, the usefulness of identifying melt-origin pseudotachylytes justifies retaining this name in its original sense.

Pseudotachylytes have a wide variety of habits and colors in the field (Fig. 3). They are usually recognized by their sharp, intrusive boundaries, dark color, aphanitic groundmass, and quench-related textures (Figure 3A; Sibson, 1975, Lin, 2008, Ch. 4; see Table 1 of Kirkpatrick and Rowe (2013)) for detailed descriptions.) These general field criteria do not describe some of the more diverse examples of pseudotachylytes which have been recently discovered. For example, pseudotachylyte in granular rock (e.g. within fault gouge, or in some sedimentary rocks) may have tortuous contacts deformed by granular flow (Fig. 3B,C), (Rowe et al., 2005, Brodsky et al. 2009 Meneghini et al., 2010). Even mild degrees of recrystallization or post-seismic deformation obscure the primary fabrics (e.g. Allen and Shaw, 2011; Price et al., 2012). Thus, the apparent rarity of pseudotachylytes in exhumed faults may be best explained by the difficulties associated with

preservation and field identification (c.f. Sibson and Toy, 2006; Kirkpatrick et al., 2009, Kirkpatrick and Rowe, 2013). The distinction between cata- 
clasite and pseudotachylyte may be clear in some environments (Pittarello et al. 2008), but when the melt fraction is very low, and clast fraction very high and fine grained (e.g. Lin, 1996; Otsuki et al., 2005, Lin, 2008; Meneghini et al., 2010; Bjørnerud, 2010), it is clear that models relying on temperature alone (c.f. Sibson, 1975) do not describe the formation of this fault rock. Indeed, Philpotts (1964) used "pseudotachylyte" to describe a combination of cataclastic and melted fault rock.

Pseudotachylyte melting models usually use melting temperatures of dry, unaltered wall rock, and link heat production to the coefficient of friction, which may change during slip (e.g. Sibson, 1975; Cardwell et al., 1978). These models involve very high temperatures of fusion for feldspar $(\sim 1100$ $\left.1500^{\circ} \mathrm{C}\right)$ and quartz $\left(\sim 1700^{\circ} \mathrm{C}\right)$ (Spray, 2005,2010$)$. The growth of high temperature $\left(>1200^{\circ} \mathrm{C}\right)$ microcrystallites during melt cooling (e.g. mullite, Moecher and Steltenpohl (2009); Allen et al. (2002) and dmisteinbergite, Nestola et al. (2010)) support the inferences of temperature spikes far in excess of equilibrium solidus temperatures of the wall rock, consistent with superheating of pseudotachylyte melt. Given heat diffusion constraints, and the short duration of heating, peak temperatures near the solidus would result in fractionation gradients. This is seen in the preferential inclusion of hydrous minerals into pseudotachylyte melt (Maddock, 1992; Lin and Shimamoto, 1998). Bulk melting, reported in many published examples of pseudotachylyte, is consistent with superheated conditions. Thus, identification criteria for pseudotachylytes include any textural characteristic of extreme temperature gradients, including quench textures, rapid growth of acicular and skeletal microcrystallites during cooling, and extremely fine grain size (Di Toro and Pennacchioni, 2004, Kirkpatrick and Rowe, 2013).

Compositional evidence suggests that many pseudotachylytes form from a comminuted and/or altered cataclasite (formed during a prior slip event, or earlier in the same slip event; Maddock, 1992; Magloughlin, 1992; Mittempergher et al. 2014). The thermal work required to melt a wet gouge is substantially less than that required to melt fresh wall rock, which is an important consideration for extracting energy estimates for earthquakes from pseudotachylyte-bearing faults. Until recently, pseudotachylytes were thought to form only in strong dry rock, as it was argued that any appreciable presence of pore fluids would result in thermal pressurization and reduce frictional heating (Rempel and Rice, 2006, Rice, 2006). However, occurrences of pseudotachylyte in wet, cool metasedimentary rocks in subduction complexes are not well explained by this model (e.g. Figure $3 \mathrm{~B}$; Bjørnerud, 2010; Rowe et al., 2005; Meneghini et al., 2010). Bjørnerud and Magloughlin (2004) suggested that coseismic decompression in dilational jogs might trig- 

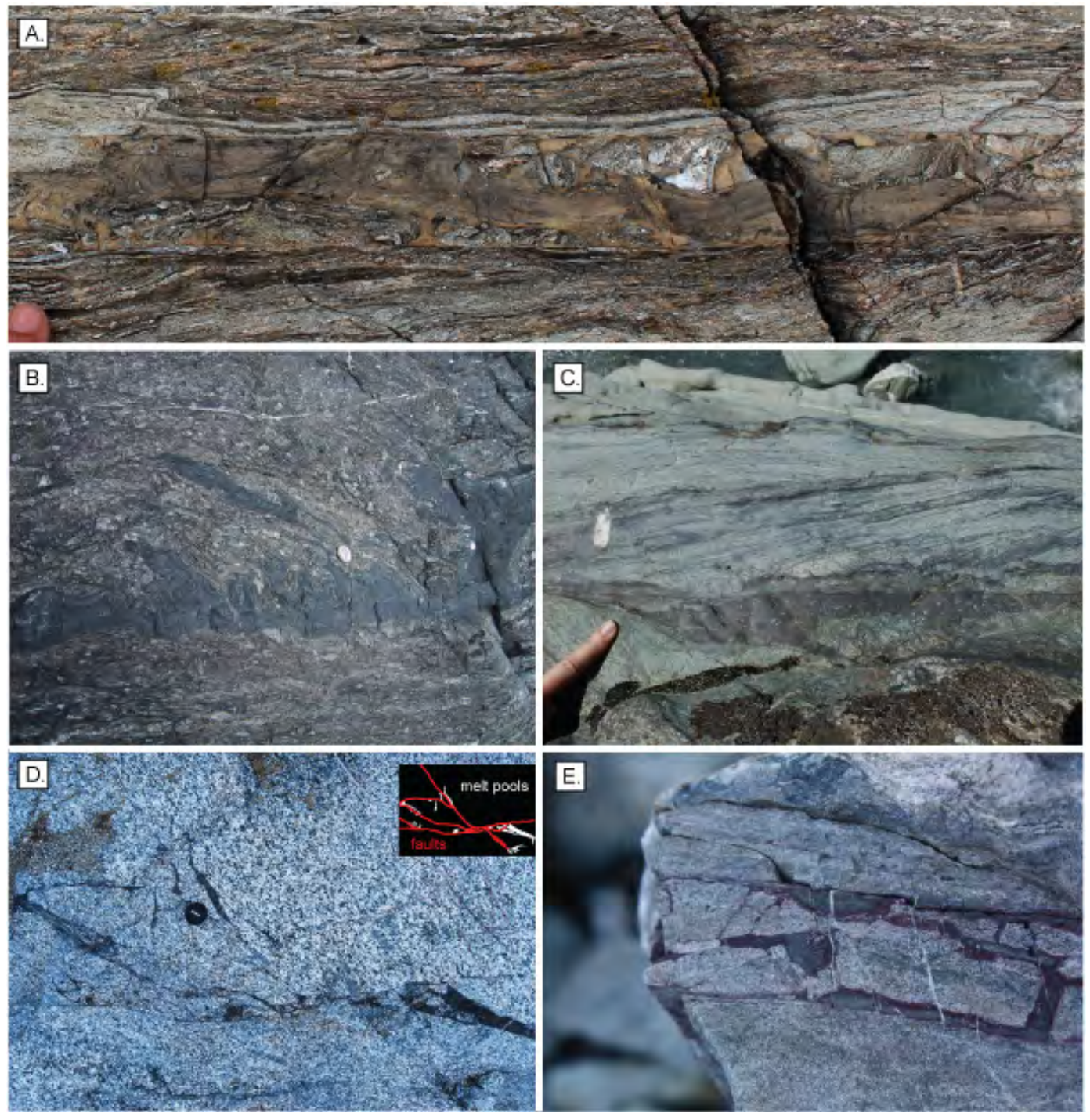

Figure 3: Pseudotachylyte vein geometries. A: Flow banding, injection, clast rotation and partial melting in a thick pseudotachylyte vein in a stepover zone between two simultaneous rupture surfaces, Fort Foster, Maine. See Swanson (2006b) for details. B: Irregular bodies of clast-rich pseudotachylyte deformed by granular flow of wall rock mélange, Pasagshak Point thrust, Alaska. Photo: Asuka Yamaguchi. See Brodsky et al. (2009); Meneghini et al. (2010) for details. C: Pseudotachylyte (purple) cutting across layered pseudotachylyte and greenstone gouge, incorporating clasts along tortuous lower surface. Photographed in float from the Moonlight Fault (Alpine Fault Zone, New Zealand, on a tip from R. Sibson). D: Hairline fault veins intersect and crosscut one another, with melt pooling in intersections, high angle tension fractures, and dilational sites created by shifting of wall rock blocks between the multiple fault strands; Santa Rosa mylonite zone, California. E: Pseudotachylyte melt mixing and filling tensile cracks between adjacent fault veins, demonstrating synchronous shearing on two sub-parallel faults; Sierra Nevada, California. 
ger melting, which is consistent with observations of discontinuous patches of pseudotachylyte along continuous fault surfaces, indicating local (metersscale) stress conditions are important for controlling frictional heating (Kirkpatrick and Shipton, 2009; Griffith et al., 2010), (Figure 3D).

When the identification of melt-related pseudotachylyte is clear, field and micro-structural observations can provide constraints on earthquake source parameters (Figure 3), (Nielsen et al., 2008). For example, pseudotachylyte vein geometries suggest co-seismic stress orientations, preserving information about rupture energy and directivity (Di Toro et al., 2005; Di Toro and Pennacchioni, 2005), and the stress magnitudes in the wall rock during rupture (Rowe et al., 2012a; Griffith et al., 2012). When the slip in a single event can be measured or inferred, it is possible to estimate coseismic shear resistance (Di Toro et al., 2006a b) and stress drop (Ujiie et al., 2007, Kirkpatrick et al., 2012). Arrays of intersecting and crosscutting pseudotachylytes can be used to determine whether slip surfaces are re-used in multiple large earthquakes (Figure 3E; Allen, 2005) and show that deformation mechanisms can vary along strike during a single rupture (Kirkpatrick and Shipton, 2009). Thick layers and accumulations of pseudotachylyte in fault overlaps and intersections suggest that multiple fault surfaces may slip during the same seismic event (Figure 3A, B, E) (Sibson, 1975, Swanson, 2005, 2006b).

Studies of pseudotachylytes overprinted by, and mutually crosscutting with, mylonites and ultramylonites dominated by crystal plastic deformation, have made clear that frictional melting occurs at the base of the seismogenic zone, and into the transitional zone where strain-rate fluctuation due to down-dip propagation of rupture may result in fast slip even where rocks are plastic at tectonic strain rates (e.g. Lin et al., 2005, Allen, 2005; Allen and Shaw, 2011; Moecher and Steltenpohl, 2009; Price et al., 2012; Shaw and Allen, 2007). In quartzofeldspathic rocks, this transition zone appears to correspond to deformation at temperatures around $300-450^{\circ} \mathrm{C}$ (Shaw and Allen, 2007), or around the greenschist to greenschist-amphibolite facies transition. Field observations of brittle deformation at higher temperatures (Swanson, 2006b; Price et al. 2012) confirm that ancient faults contain records of this localized, rate-dependent behavior. Pseudotachylytes have been reported from locations deeper and hotter than the typical seismogenic zone, where rocks were actively creeping by crystal plastic deformation when localized slip occurred (Lin et al., 2003, Austrheim and Andersen, 2004; Lin et al. 2005; Behr and Platt, 2011: White, 2012, and summary therein).

This wealth of field studies of pseudotachylyte, and integration with experiments and geochemical analyses, have enabled the study of earthquake 
source parameters at the source. The continuing discoveries of new field sites in diverse lithologic and tectonic environments hold continuing promise for future insights.

\subsubsection{Frictional devolatilization}

Frictional heating during seismic slip may be recorded, even when peak temperature does not exceed the local fault rock solidus. In particular, hydrous and carbonate minerals have been shown to thermally dissociate during fast slip. Dissociation leaves volatiles and amorphous or nano crystalline materials that are potentially reactive with fluids and surrounding minerals, and unstable over geologic time (e.g. CaO, Han et al., 2007b). The recrystallization of these products may occur immediately post-seismically, or after the fault has cooled. In the former case, the new minerals may record higher than ambient temperatures, or in the latter, the pre-seismic mineralogy may be reproduced by back-reaction of the dissociation products. Friction experiments on rocks with high volatile content have shown that considerable energy is consumed in the devolatilization reactions associated with the breakdown of some minerals (Sulem and Famin, 2009, Brantut et al., 2010, 2011), as predicted by Billi and Di Toro (2008). Vaporization of the released volatiles consumes frictional heat, buffering the temperature rise on slip surfaces during seismic slip. This effect may be important only in minerals that lose a significant proportion of their mass to volatilization, including carbonates and sulfates, which comprise a tiny fraction of earth's crust but may be locally abundant in some fault zones. Below we describe some case studies, from natural faults and from shearing experiments, which suggest that a structural record of frictional devolatilization may be formed under common conditions in appropriate lithologies in the seismogenic zone.

Carbonates. Carbonate minerals (predominantly dolomite and calcite) can be broken down by fast heating to release $\mathrm{CaO}, \mathrm{MgO}, \mathrm{FeO}$, and $\mathrm{CO}_{2}$. Dolostone is formed by the diagenetic or metamorphic alteration of limestone (Baker and Kastner, 1981), so they are often found in association, but the rheologic properties are significantly different. Dolostone displays a higher friction coefficient and yield strength than limestone (Austin et al., 2005, Billi and Di Toro, 2008; Di Toro et al., 2011). Iron-carbonates (siderite and ankerite) have a similar crystal structure to dolomite, but they are rarely dominant rock-forming minerals. The carbonate minerals break down at temperatures of $\sim 600-800^{\circ} \mathrm{C}$ to release $\mathrm{CO}_{2}$, leaving nano particles of calcium, iron and magnesium oxides, and hydrated equivalents due to moisture available from the laboratory atmosphere (De Paola et al. 2011b). The 
conditions of dissociation, and the nature of the reaction products vary with the mineralogy of the carbonate rock, time-temperature path, water activity and presence of organic and inorganic impurities (Bhatty, 1991).

Han et al. (2007a; 2007b) showed that frictional decarbonation (calcining) in high speed friction experiments on siderite and calcite produced oxide nanoparticles that lubricated experimental faults. The resulting drop in shear strength could be influenced by the unique superplastic rheology of nano particle aggregates (De Paola et al., 2011b; Han et al., 2011; Verberne et al. 2014), and also potentially by pore pressurization due to release of $\mathrm{CO}_{2}$, although this effect was weaker in the unconfined experiments. The experiments showed that the remaining nanoparticles could crystallize almost instantaneously to form oxide minerals in the gouge (e.g. siderite, magnetite; Han et al., 2007b).

Characteristic textures indicative of thermal dissociation have been identified in friction experiments and correlated to observations in a number of faults (e.g. the Naukluft Thrust, Figure 4A, B; Rowe et al. (2012a)). De Paola et al. (2011a) demonstrated that dolomite dissociation due to fault slip could produce $\delta^{13} C$ and $\delta^{18} O$ decreases in residual the fault rock and $\mathrm{CO}_{2}$ concentration increases in ground water. Skeletal, decomposed carbonate grains were reported in the wallrock of the experimental faults, showing that heat produced on the slip surface was sufficient to raise the temperature of the wallrock above the dissociation threshold (Han et al., 2010). However, a clumped isotope study designed to detect high temperatures on a carbonate-hosted fault found temperatures of carbonate crystallization only slightly above ambient temperature (Swanson et al. 2012). Thus, if carbonate dissociation occurred, recrystallization followed after the fault had cooled back to ambient conditions.

Field observations of carbonate-hosted faults show evidence for coseismic decarbonation, even though some of the features produced in the laboratory, such as reactive nano particles, are extremely short-lived in the geological environment. Diagnostic microstructures include direct effects of fast heating, such as skeletal porosity in surviving crystals (Collettini et al. 2013, Mitchell et al. 2015). Spherules of carbonate, including grain coatings, may reflect adhesion of nano particulate decarbonation products (Beutner and Gerbi, 2005, Craddock et al., 2012; Rowe et al., 2012a; Mitchell et al., 2015), but distributed coated clasts may be produced by different mechanisms at different slip rates (Smith et al., 2011; Rempe et al., 2014, and section 3.2.3 below). Co-seismic fluidization of carbonate fault rock has been attributed to pore pressure transients caused by decarbonation (Smith et al., 2008, Rowe et al. 2012a; Craddock et al., 2012) (Figure 4A). Further evidence for 
$\mathrm{CO}_{2}$ liberation during earthquakes includes the observation of post-seismic $\mathrm{CO}_{2}$ emissions in carbonate terrains (Bonfanti et al., 2012).

Even when peak temperature is insufficient to destroy carbonate minerals, the effects of transient heating may be recorded by the stretching of crystals, resulting in increase in volume of fluid inclusions (Ujiie et al., 2008). Carbonates may also preserve records of sudden chemical changes during faulting, either by fluid mixing or by $\mathrm{pH}$ changes driven by fluid interactions with fresh broken mineral surface area (Yamaguchi et al. 2011a). Ankerite precipitation is preferred in these reduced conditions. Either of these mechanisms provides a clear link between carbonate vein chemistry and fault slip, although the interpretation of rate dependence is not as tightly constrained as for some of the other fault rock records.

Hydrous silicates. Hydrous silicate minerals such as clays and micas are vulnerable to damage or dissociation due to coseismic frictional heating (Table 1). These reactions drive off water from interlayer sites in expandable clays at low temperature, release bound water in the crystal lattice of hydrous minerals at moderate temperatures, and, at high temperature, destroy crystalline structure (Grim and Bradley, 1940; Tschegg and Grasemann, 2009 Mizoguchi et al. 2009). The freed water may contribute to thermal pressurization, and the remnant material may be released into solution in pore water, remain as crystalline or amorphous nanoparticles, or form new minerals upon cooling. Laboratory experiments demonstrate the rapidity of these reactions. Hirose and Bystricky (2007) showed that heterogeneous heating on a slip surface in an experimental fault allowed for dehydration of serpentine (at $\sim 500^{\circ} \mathrm{C}$ ) even when the average fault temperature was only $\sim 200^{\circ} \mathrm{C}$. Silica and alkalis from broken-down clays may recombine to form new clay minerals after the event, or may form amorphous patches (Collettini et al., 2013) or cements of quartz, feldspar, or zeolite (Rowe et al. 2012b).

In shallow faults where ambient temperatures are $<150^{\circ} \mathrm{C}$, smectite clays (e.g. montmorillonite, saponite) are important constituents of fault gouge (e.g. Rutter et al., 1986; Lockner et al., 2011; Tesei et al., 2012, Chester et al., 2013). The instability of these minerals at higher temperatures means that frictional heating can be recorded in clay reactions. Observations of ancient faults have suggested that the transition of smectite to illite may be accelerated in seismic slip surfaces (Yamaguchi et al., 2011b); however, the kinetics of this reaction at high heating rates are not well understood. At temperatures $<250^{\circ} \mathrm{C}$ and short duration (minutes), or if potassium is limited, smectite may not transform to illite. Instead, the interlayer water will 

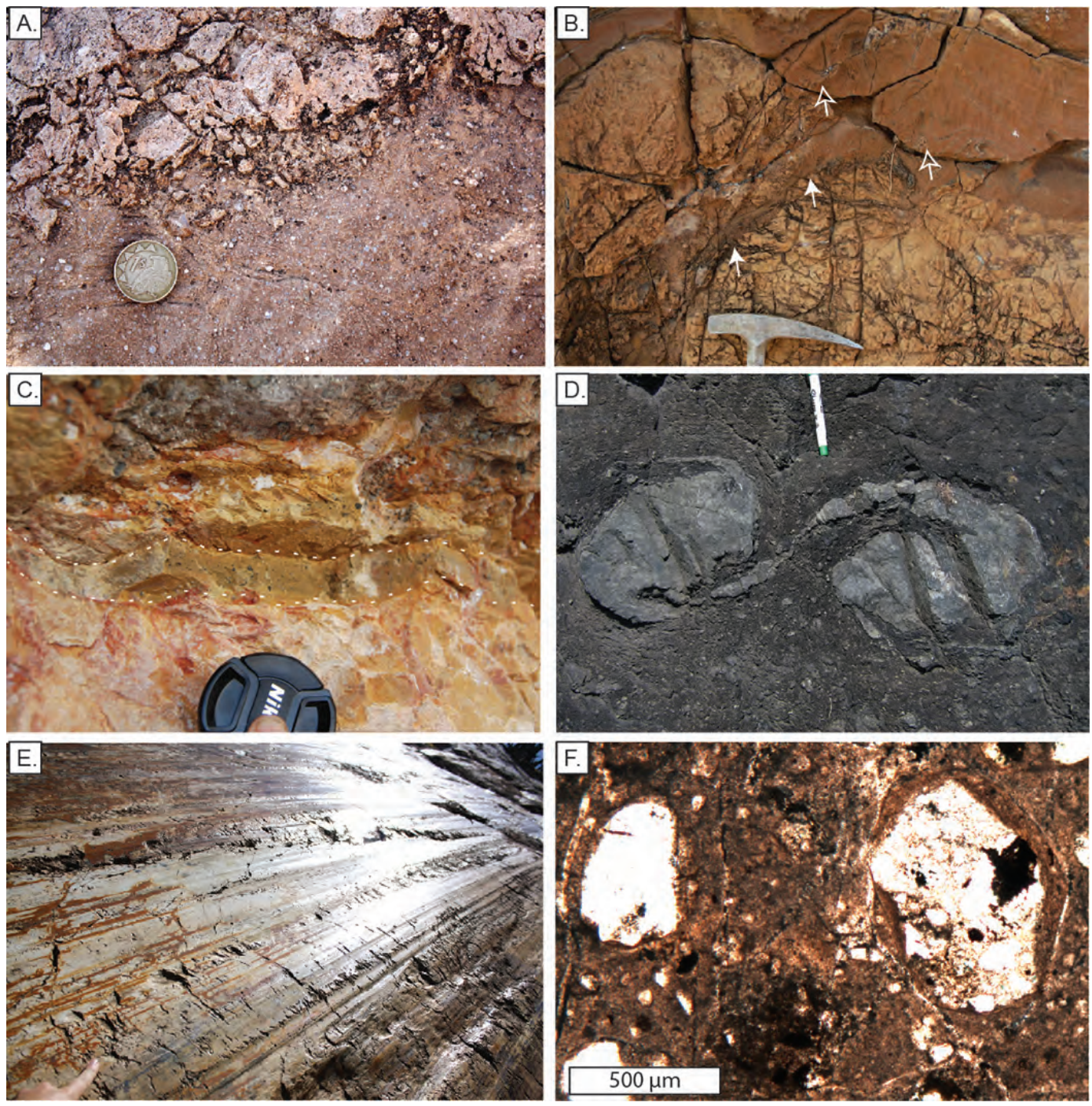

Figure 4: Features of natural fault gouges. A: Fragmentation of dolostone wall rock (top of photo) associated with decarbonation and flow in massive gouge layer, with incorporation of wall rock fragments into gouge. Naukluft Thrust, Namibia (Rowe et al., 2012a). B: Fluidized dolomite gouge shows grain size lamination folded (open arrows) and injected into cracks in wallrock (filled arrows). Naukluft Thrust, Namibia (Sherry, 2014) C: Cohesive cataclasite layer with concoidal fracture within gougey fault core, Muddy Mountain Thrust, Nevada. D. Fluidized flow in 15 m-thick cataclasite layer in Pasagshak Point Thrust. Clasts of partially consolidated sandstone grow tails through internal granular flow (Rowe et al. 2011). E: Mirror surface of Corona Fault, San Francisco, California. F: Cortex-clasts in cataclasite, Corona Fault, California. Cortexes on quartz grains are made of silica and iron oxides CCAs are found within mirror surface of cryptocrystalline to amorphous silica (Kirkpatrick et al., 2013). 
be driven off, collapsing the smectite structure, reducing the crystals' ability to rehydrate (Schleicher et al., accepted), and altering the frictional properties (Ikari et al., 2007). Although not detectable by most routine analyses, this permanent heat-damage may be detected by X-ray diffraction under humidity-controlled conditions (Schleicher et al., accepted). Metamorphosis of smectite to chlorite has been reported in cataclasite from a subduction thrust and may be combined with chlorite geothermometry to estimate coseismic temperature rise (Kameda et al. 2011). Both these reactions appear to record temperature rise of $\Delta T=100-200^{\circ} \mathrm{C}$ at depths from near surface down to a few $\mathrm{km}$.

At higher temperatures, clays may melt or decompose, resulting in silica cementation and facilitating new mineral growth upon cooling. Clay mineral collapse and/or partial decomposition and resultant sintering likely contribute to forming sharp layers of durable cataclasite commonly found in otherwise incohesive, gougey fault cores (Figure $4 \mathrm{C}$ ). Clay firing experiments suggest decomposition and reaction is most vigorous at $\sim 650-800^{\circ} \mathrm{C}$ (Tschegg and Grasemann, 2009), but further work is required to determine whether these experiments performed under fully oxidizing conditions are relevant to clay gouge in the earth. Iron oxides formed from breakdown of smectite may impart magnetic properties to fault gouge (Hirono et al., 2006 , Mishima et al. 2006) at estimated peak temperatures of $>400^{\circ} \mathrm{C}$. Layers of black fault gouge recovered from the Chelungpu fault showed evidence of selective clay breakdown, with different temperature ranges in different slip zones recorded by differential survival of different types of clays (Kuo et al., 2009). These reactions can be roughly calibrated to temperature/time through comparison to the products of laboratory heating experiments (e.g. estimated peak temperature $=350-1000^{\circ} \mathrm{C}$ for three slip surfaces in the Chelungpu Fault, Kuo et al., 2011).

Clay minerals are sensitive to both transient and long-term temperature changes (Table 1). Although accurate identification of individual clay species, and detection of thermal damage or amorphization, are timeconsuming and laborious, the studies of clays in faults are extremely promising for determining thermal history of fault zones.

\subsubsection{Maturation of organic material}

The thermally-mediated maturation of organic material in sedimentary rock has long been used for assessing the thermal maturity and temperatureburial history of reservoir rocks (Barker and Pawlewicz, 1986, Burnham and Sweeney, 1989: Sweeney and Burnham, 1990). These techniques have been recently adapted for measuring fault heating. The most common of the or- 
ganic materials to be analyzed in this way is vitrinite, a maceral derived from the burial of woody material (Teichmüller and Teichmüller, 1979). Vitrinite particles become more reflective with increasing temperature (reported as the percentage of light reflected from particles immersed in oil, $R o \%)$. This reaction is relatively insensitive to heating duration at long timescales (e.g. on the order of burial rates, Barker and Pawlewicz, 1986). Elevated vitrinite reflectance along faults cutting the vitrinite source rock were initially attributed to differential frictional heating of the fault surfaces (e.g. Bustin, 1983, Suchy et al., 1997; O'Hara, 2004), but mounting evidence suggests that deformation, not just temperature, plays a role in vitrinite maturity (Dalla Torre et al., 1997; Carr, 2000), probably due to shear strain producing increased order in the basic structural units and straightening of layers within the molecular structure Ross et al., 1991; Wilks et al., 1993). Most importantly for fault studies, increases in vitrinite reflectance during shearing experiments at low velocities have demonstrated that shear alone, even without temperature rise, can increase vitrinite reflectance by polishing. This effect is demonstrated in anomalously high temperatures calculated from vitrinite reflectance in fault rocks compared to other temperature proxies (Hirono et al., 2009: Sakaguchi et al., 2011) which are not well explained by fault heating alone (Fulton and Harris, 2012).

Organic molecules, abundant in most sedimentary rocks, also mature with time-temperature path and do not appear to be vulnerable to the stress and strain effects observed in particles of vitrinite. Initial studies on fault rock showed that thermal maturity indices increased in a pseudotachylytebearing fault (Savage et al., 2014), but not in an extinct, exhumed strand of the San Andreas (Polissar et al., 2011). These results show that frictional temperature rise on short timescales is recorded by sedimentary organic molecules. Experimental calibration of the reaction rates on timetemperature paths similar to those expected on fault surfaces during seismic slip may enable precise determination of peak temperature in the future (Rabinowitz et al., 2013; Sheppard et al., 2015).

Faults in coal-rich rocks may show evidence for thermal reduction, such as the formation of graphitic layers in anthracite fault gouge around the rupture surface of the 2008 Wenchuan earthquake (Kuo et al. 2014). Laboratory shearing experiments on carbonaceous materials are most effective at producing graphite at elevated normal stress, (O'Hara et al., 2006, Oohashi et al., 2011; Kuo et al., 2014), suggesting that thermal reduction/decomposition of organic matter is the likely source for graphite in the gouge. Oohashi et al. (2011) showed dramatic weakening when amorphous organic carbon was transformed to graphite at slip rates of a few $\mathrm{cm} / \mathrm{s}$. 
Conversely, ductile shearing may reduce the crystallinity or even amorphize graphite in fault rocks, so the frictional strength of carbonaceous rocks may be highly variable during deformation (Nakamura et al., 2015).

\subsubsection{Trace element mobility}

The partitioning of trace elements between pore fluids and minerals is strongly temperature dependent. At finer grain sizes, increased surface area enables rapid diffusion and equilibration between fluids and fault gouge. The temperature dependence has been used by Ishikawa et al. (2008) and subsequent workers to estimate paleoseismic peak frictional heating from trace element concentrations in fault rock. The method works by comparing trace element ratios in fault rock to trace element ratios in neighboring rock away from the slip surface, which is assumed to have similar initial chemistry but different thermal history. It is also assumed that the fault rocks and wall rocks were in contact with the same pore fluids. Any differences in trace element distribution can be attributed to equilibration at different temperatures, which can be constrained through diffusion modeling. Rates of diffusion increase exponentially with temperature, thus, equilibration is most efficient at peak heating, and slower diffusion during cooling is incapable of overprinting the peak effect. This proxy for frictional heating has now been successfully applied in several active and ancient faults, revealing temperature spikes up to $\sim 350^{\circ}$ in faults from only a few $\mathrm{km}$ depth (Hirono et al., 2009; Honda et al., 2011; Hamada et al., 2011; Yamaguchi et al., 2014).

\subsection{Potentially earthquake-related}

In this section, we describe deformation mechanisms and resulting structures thought to be associated with seismic slip, but around which some ambiguity remains. Some of these phenomena certainly occur at high slip rates, but the minimum bounds on slip rates are poorly defined or are specific to local conditions, and they may also record sub-seismic slip rates. Others have not been reported in enough environments or studied in enough detail to make generalizations about the slip conditions of formation.

\subsubsection{Fluidized granular flow}

Granular fault rocks such as breccia and gouge (Figure 4, 5A) may be mobilized during fault slip. Fluidized grains may move along- or off-fault following pressure gradients, injecting into wall rock fractures and pooling in dilational sites on fault surfaces (e.g. Kirkpatrick and Shipton, 2009, Rowe 


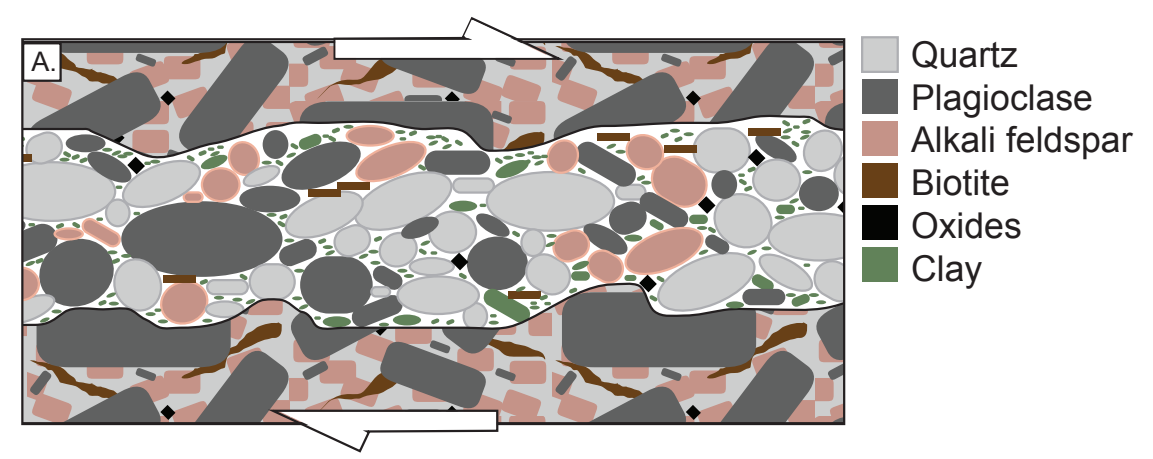

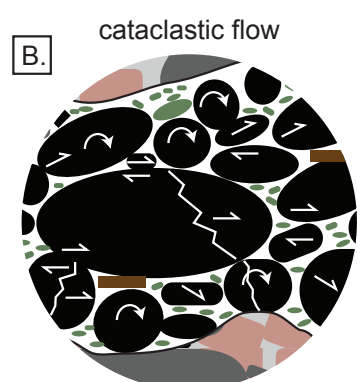

Rotation, sliding and fracture

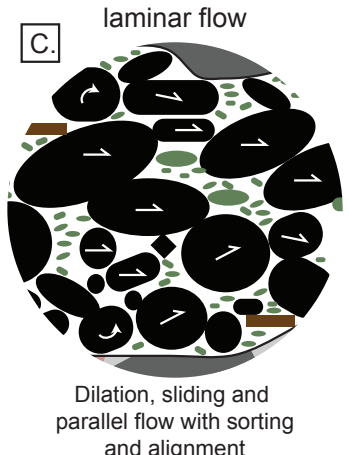

and alignment

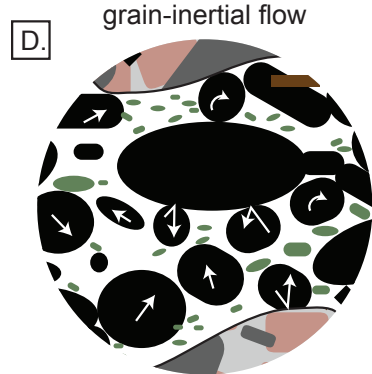

Collision-dominated momentum transfer, increased dilation, particle paths random, size and alignment well-mixed

\section{Increasing slip rate, increasing dilation, decreasing shear resistance}

Figure 5: (a) Natural gouge in granite consists of different size fractions of host rock minerals as well as alteration minerals, such as clays, which are not found in the host rock. Multiple flow mechanisms may act in the gouge layer during the same slip event. (b) Cataclastic flow (c) Laminar flow (c) Grain-inertial flow

et al. 2012a; Fagereng et al., 2014). Mobilized granular rock is well documented in fault planes and landslide slip surfaces (Beutner and Gerbi, 2005, Smith et al., 2008; Rowe et al., 2012b) (Figure 5B). Fluidization may also occur in unconsolidated sediments (e.g. Sherry et al., 2012; Quigley et al., 2013 Loope et al. 2013), and these can sometimes be distinguished from sediment mobilization by other triggering mechanisms (Owen et al. 2011, Rowe, 2013) to create a regional record of paleoseismicity. Such features are often called paleoseismites, but as this paper is focused toward on-fault phenomena, we will not explore them further.

Granular flows may be divided into cataclastic and fluidized flows (e.g. 
Borradaile, 1981). This distinction may be relevant for interpreting past flow velocity, although different styles can probably occur in the same fault, possibly during the same slip event (Figure 4A). Cataclastic flow occurs when particles in contact with each other roll, slide, and crack to achieve distributed shearing through a layer of grains (Rutter, 1986) (Figure 4A, 5B). Stress-dependent trade-offs between fracturing and dilation during cataclasis result in grain size reduction and the development of fractal grain size distributions, with predominantly angular grains (An and Sammis, 1994). This process does not appear to be rate-dependent, and may produce similar fault rock textures during creep as during seismic slip (Stünitz et al. 2010). Such shearing may be well-described by laboratory-derived friction laws (Marone, 1998), as this is the deformation mechanism typical of unconfined gouge with negligible pore pressure.

Fluidized granular flow may be laminar (continuous) or "grain-inertial" (turbulent, discontinuous). Fluidized granular flow operates with direct transfer of momentum from one grain to another, but the flowing grains ( \pm pore fluid) may be treated in bulk as single phase flow. The interparticle stresses are lower than in cataclastic flow, and grain breakage is less pervasive (Rawling and Goodwin, 2003; Mair and Abe, 2011). When grains do fracture, the fragments are rapidly rotated or bounced away from one another, so that matching them in thin section is rarely possible (Monzawa and Otsuki, 2003). Describing fluidized granular flow this way is similar to the method employed for debris flows, lahars, and some types of landslides where inertial forces are significant (Okura et al., 2002).

In ancient faults, evidence for past fluidization of gouge is often inferred from the granular texture. Indicative features include: sharp (sometimes cuspate-lobate) boundaries crosscutting adjacent layers, plucking and sorting of clasts of wall rock and older gouge or cataclasite, and injection of gouge into off-fault cracks (e.g. Monzawa and Otsuki, 2003; Otsuki et al., 2003 Boullier et al., 2009; Brodsky et al., 2009; Fondriest et al., 2012; Rowe et al. 2012b). Gouge or cataclasite with microstructure indicative of past granular flow has been found in geometric relationships with pseudotachylyte that suggest coseismic formation of both fault rocks (Otsuki et al. 2003 , 2005 Kirkpatrick and Shipton, 2009, Meneghini et al., 2010). The effect of shaking likely also contributes to granular fluidization (Monzawa and Otsuki, 2003 Owen and Moretti, 2011), as experiments show that shaking separates grain contacts, reducing intergranular friction and causing the initiation of flow Rodrigues et al., 2009, van der Elst et al., 2012, Yasuda and Sumita, 2014). The similarity of injection vein morphology and orientation between granular injections and pseudotachylyte injections led Rowe et al. (2012a) 
to conclude that similar coseismic wall rock stresses could be interpreted for both types of features.

Laminar flow tends to sort grains across flow velocity gradients and align non-equant grains sub-parallel to flow lines (Figure 5C). Thus, granular layers which are grain-size and/or density segregated in planar layers, often parallel to the fault walls, and show grain preferred orientation parallel to the layering, must be produced by laminar grain flow (Cladouhos, 1999, Ujiie et al., 2011; Ismat, 2013). This texture is characteristic of shallow fault gouges collected from many recently active faults (e.g. Cowan et al. 2003 Smith et al., 2008; Bradbury et al., 2011; Boulton et al., 2012) and granular fault injections (Lin, 1996; Boullier et al., 2009; Rowe et al., 2012b) (Figure 4B,C).

Grain-inertial flow ("gas-phase" of Campbell, 1990) occurs when particle paths are independent of one another and of the motion on the fault (Figure 5D). Momentum transfer occurs by grain collisions. The granular rock is internally pressurized, with reduced effective normal stress on the fault (Melosh, 1979; Sulem et al., 2007). If a granular flow collapses directly from an inertial state to a locked/compacted state, fault rock textures may preserve evidence of inertial fluidization, including well-mixed grains (by size and density), massive texture lacking foliation, and random grain orientation (Rowe et al., 2011). Numerous examples of massive textured, unsorted gouges and cataclasites (e.g. Figure 4A) have been attributed to coseismic fluidization, particularly by thermal pressurization (Rowe et al., 2005; Ujiie et al., 2010; Lin, 2011; Ujiie et al., 2011), although it is not proven with certainty that these features are uniquely associated with this type of flow.

The evidence suggests that both inertial and laminar grain flow occur in gouge during seismic slip, but the mode depends on viscosity of the aggregate, which depends on pressurization, so has an indirect dependence on slip rate. While inertial granular flow is necessarily fast (on order $\mathrm{cm} / \mathrm{s}$ $\mathrm{m} / \mathrm{s}$; Sherry et al., 2012, Ross et al., 2014) the precise dependence on fault slip rate has not been established. The identification of diagnostic features in fault outcrops is poorly constrained, and detailed structural context is essential to interpret the style and geometry of granular flow in fault gouges and breccias.

\subsubsection{Mirror fault surfaces}

"Mirror" faults are exposed slip surfaces that are smooth on the scale of visible light so they are remarkably shiny (Figure $4 \mathrm{E}$ ). They are characterized by thin layers of very fine grained fault rock coating sharp, planar to wavy slip surfaces, which often crosscut clastic fault rocks. Mirror 
faults have been reported in rocks of varied mineralogy, and their formation has been attributed to either slip-polishing, or to the development of an ultrafine-grained layer of fault rock along the principal slip surface.

The first detailed study of a mirror fault surface at "The Mirrors" locality in Dixie Valley, NV, revealed a vitreous, nearly pure quartz layer with submicron grain size, coating a self-affine surface (Power and Tullis, 1989, 1991). Micro- to nano-scale observations show irregular grain boundaries in a very high energy state configuration with no shape-preferred orientation, crosscut by thin bands of preferred crystallographic orientation (Power and Tullis, 1989). Similar microstructures were observed in a thin reflective layer on the surface of the Corona Heights Fault, California (Kirkpatrick et al., 2013), and a quartz fault vein in carbonate/shales in Namibia (Faber et al., 2014). While Power and Tullis (1989) interpreted the thin layer as a hydrothermal vein modified by inter-granular pressure solution formed during slow creep, Kirkpatrick et al. (2013) and Faber et al. (2014) both identified relict silica colloids and (for Corona Fault) amorphous patches within the layer, and inferred solidification and partial crystallization of a silica gel formed by seismic slip along the fault (also see Section 3.2.5).

Mirror surfaces have also been reported in carbonates (Fondriest et al. 2013, Siman-Tov et al., 2013, Collettini et al., 2014). Fondriest et al. (2013) showed that formation of mirror surfaces is related to frictional power density (sensu Di Toro et al., 2011). Siman-Tov et al. (2013) showed that the extremely smooth surfaces are formed by a thin layer of sub-spherical carbonate nanoparticles filling in the micron-scale roughness of the fault gouge or rock surface beneath.

A recent report of iridescent slip surfaces in the Wasatch Fault, Utah, suggests that preexisting hematite in faults may react to iridescent, shiny reduced Fe fault veins due to frictional heating (Evans et al. 2014). Claysmeared faults in shales may attain mirror-like smoothness (Lindsay et al. 1993). The common feature of mirror faults in different lithologies is their micron-scale smoothness, but the mechanisms by which they form are not necessarily similar.

Micro- to nano-granular shiny surfaces were generated in experiments on diorite and quartzite (Goldsby and Tullis, 2002; Di Toro et al., 2004, Hirose et al. 2012) and on carbonates (Han et al., 2011; Tisato et al., 2012, Chen et al. 2013, Fondriest et al. 2013, Smith et al., 2013b; Verberne et al., 2013) at a range of slip velocities. With the establishment of the shiny surface, frictional wear rate is much reduced (Hirose et al., 2012). The available data generally suggest that mirror faults do not form without elevated temperature on the slip surface (with thermal breakdown of calcite and the appear- 
ance of periclase and calcite in dolomite, Fondriest et al., 2013; Smith et al., 2013b). Extremely smooth localized slip surfaces are commonly noted in rotary shear experiments which display velocity-weakening behavior, often associated with mineral transformations (e.g. Oohashi et al., 2011; Smith et al., 2013b; Lamothe et al., 2014). Thus, it is clear that mirror surfaces can be formed by extreme localization during high-velocity slip. To our knowledge, no similar surfaces have been formed during slip experiments at sub-seismic slip velocities. However, as the mechanisms of formation may vary by lithology and normal stress, it may be important to test a wide range of materials and conditions in order to place reliable constraints on the formation of fault mirrors.

\subsubsection{Clast-cortex aggregates}

Warr and Cox (2001) first described "snowballed' smectite rims around rotated quartz grains in gouge from the Alpine Fault and inferred formation of these coated grains during granular flow under high pore pressure conditions. Clay-clast aggregates or clast-cortex aggregates (CCA) were subsequently described from gouge layers interpreted to represent seismic slip surfaces of the 1999 Chi Chi earthquake (Boutareaud et al., 2008; Boullier et al., 2009, Boutareaud et al., 2010). These clasts consist of core grains (often quartz, feldspar, lithic clasts or clasts of older cemented gouge) with concentric coatings of smaller particles. The coatings are about 5-10 $\mu \mathrm{m}$ thick and approach a spherical shape with increasing thickness, regardless of the shape of the core clast. CCA are not always ubiquitous in the gouges that contain them; coated grains are mixed among grains with no coatings (Boutareaud et al. 2008; Boullier et al., 2009). The CCA were reproduced in both wet and dry rotary shear experiments at $\sim 1 \mathrm{~m} / \mathrm{s}$ (Boutareaud et al. 2008, 2010). Ferri et al. (2010) produced similar structures adjacent to the principal slip zone in gouge from a landslide slip surface. In all these cases, liquid-vapor transition in pore water was interpreted to cause the formation of CCA, in association with fluidized granular flow under thermally pressurized conditions.

Subsequent experiments have shown that CCA in clay-rich gouge can be produced at a range of slip conditions. Ujiie et al. (2011) produced CCA during dry faulting, but wet faulting under the same shearing conditions formed sorted, foliated gouge without CCA. Han and Hirose (2012) were able to produce CCA in dry gouge at slip rates down to $500 \mu \mathrm{m} / \mathrm{s}$. They also produced cortex grains in silica nanoparticle samples, showing that clay dehydration is not essential for producing cortex clasts. The experimental examples strongly mimic natural examples from a chert-hosted fault (Fig- 
ure 4F; Kirkpatrick et al., 2013).

Similar grain morphologies have been reported in carbonate-hosted faults and landslides, under similar interpreted conditions of deformation (Beutner and Gerbi, 2005; Smith et al., 2011, Rowe et al., 2012b). Fine-grained calcite cortexes adhered to calcite fragments in the principal slip zone. They associated these grains with fluidization of gouge. Rempe et al. (2014) carried out calcite gouge shearing experiments at a range of slip rates and displacements $\left(10^{-4}-10^{0} \mathrm{~m} / \mathrm{s}\right)$. Similar to the clay-clast aggregates, the carbonate CCA formed in room-dry gouges but not when pore water was added.

Thus, it appears cortex grains can be formed in $d r y$ clay or carbonate gouge at slip rates associated with earthquakes $\left(10^{-4}-10^{0} \mathrm{~m} / \mathrm{s}\right)$ at low effective normal stresses (Ujiie et al., 2011; Han and Hirose, 2012; Rempe et al., 2014). Where such information is available, it appears that the cortex grains may not form directly in the principal slip surface, but adjacent to it in a fluidized gouge layer. This slip partitioning in the experiments indicates that both temperature and strain patterns within the shearing layer (including, but not limited to, the principal slip surface) are heterogeneous. At present, the deformation and temperature dependency of the formation of cortexes is under-constrained. In all cases, the concentric, spherical structure of the cortices imply grain rolling during aggregation. The mechanism of adhering fine particles to the larger grains has been suggested to be "electrostatic" (Boutareaud et al., 2010, Han and Hirose, 2012). If so, the role of water in inhibiting cortex formation may be related to reduced inter-particle friction and triboelectric effect (Rempe et al., 2014). This effect would be expected to vary with mineralogy, temperature, moisture content, and most importantly, strain rate and degree of localization.

\subsubsection{Coseismic crystal plastic deformation}

Pseudotachylytes are commonly associated with mylonitized wall rock, but they are most often reported in crosscutting geometries which suggest the overprinting of one by the other during different intervals of deformation (e.g. Passchier, 1982; Price et al., 2012). However, a few field examples of coeval frictional melting and crystal plastic deformation of wall rock suggest that high temperatures adjacent to seismically slipping faults may persist long enough for co- to post-seismic ductile strain to reach detectible magnitudes (e.g. John et al., 2009). Bestmann et al. (2012) show an example of ductiley distorted foliation around pseudotachylyte faults, apparently developed by subgrain rotation and dislocation creep. Microshears associated with this ductile deformation contain newly developed strain-free quartz grains, potentially related to destruction and regrowth of the crystalline 
structure in quartz (see Section 3.2.5).

High temperatures associated with experimental frictional heating has caused solid state recrystallization of gouge and wall rock in halite (Kim et al. 2010) and calcite (Smith et al., 2013b). The halite experiments show thin $(100-200 \mu \mathrm{m})$ bands with ribbon-shaped halite crystals extended coaxially with the slip on the adjacent pseudotachylyte layer. The close association of crystal plastic and cataclastic fabrics may correspond to a strain rate gradient away from the slip zone (c.f. Niemeijer and Spiers, 2006). Both field and experimental examples demonstrate the feasibility of co- postseismic crystal plastic flow facilitated by frictional heating, confined to a narrow layer around extremely localized slip surfaces.

\subsubsection{Amorphous material}

Several of the co-seismic processes described above may produce amorphous material, by a wide variety of mechanisms. Frictional melt, if quenched quickly enough, may solidify to an amorphous glass, although this is almost never observed in ancient samples (exceptions include: Philpotts, 1964; Lin, 1994). Evidence of solid-state crystallization from glass in the post-seismic period may be preserved in some pseudotachylytes (Kirkpatrick and Rowe, $2013)$.

Thermal breakdown of clays can leave amorphous residue (e.g. the amorphous orange-brown silicate material of Collettini et al., 2013). Amorphous materials with similar composition to clays have been found in clay gouges, often containing tiny crystals of clay minerals with the same composition (Kuo et al., 2009, Janssen et al., 2010, 2013). These crystals may grow directly out of the amorphous material, or may be remnant, or included. Traces of amorphous material are produced in shearing experiments on clay gouges (e.g. Brantut et al., 2008). Amorphous materials develop during clay growth in soils, at conditions similar to the upper few $\mathrm{km}$ of continental faults, forming shapeless blobs out of which clay crystals grow, and coating detrital grains (Istok and Harward, 1982, Saccone et al., 2007). As the amorphous materials found in fault gouges may strongly resemble pedogenic amorphous silicates and oxides associated with wetting and drying in soils, extreme care must be taken to understand the structural context of amorphous material in fault gouges to understand its relationship to slip. When associated with corroborating evidence of thermal decomposition, as with the skeletal calcite described by Collettini et al. (2013), amorphous material of clay composition may be inferred to have been produced by coseismic frictional heating.

Amorphous material is routinely produced in relatively slow bulk de- 
formation experiments on crushed granite at room temperature up to high temperature (Yund et al., 1990; Pec et al., 2012b; White et al., 2009, 2013; Hadizadeh et al., 2015). The mechanism of amorphization is not well known, but it appears to affect quartz, feldspar and mica without significant selection by mineralogy (distinct from melting) (Pec et al., 2012b). "Gel"like coatings of amorphous material develop on sheared bare rock surfaces (White et al., 2013), while patches in crushed granite link up with increasing slip (Pec et al., 2012b). These observations suggest very little slip is required to initiate amorphization. It has been suggested that the amorphization is related to loss of structure if stress on grains remains high while grain size reduction approaches the theoretical grinding limit defined by Keulen et al. (2007). Natural examples of amorphous material potentially produced in this way have been reported (Ozawa and Takizawa, 2007), but there are insufficient reports to determine how wide-spread mechanicallyformed amorphous material may be, or whether there are any useful limits on the environments where it forms. Amorphous materials in faults may also result from hydrothermal alteration or cementation. Thus, field geometric relationships demonstrating that amorphous layers are exclusive to the principal slip surface of a fault are required for certain identification (Faber et al., 2014, Schulz and Evans, 1998, Ozawa and Takizawa, 2007).

Shear experiments in quartz rocks have produced amorphous hydrous silica ("silica gel") on slip surfaces at moderate to high slip rates, at temperatures far below quartz melting threshold (e.g. Goldsby and Tullis, 2002; Di Toro et al., 2004). Dramatic shear weakening occurs when this material is produced, but the exact mechanism of loss of crystallinity in quartz is not well understood, nor is the rheology well-characterized. Natural examples of silica layers containing amorphous silica or preserved colloids suggesting an amorphous precursor have now been reported on principal slip surfaces in two exhumed faults (Kirkpatrick et al., 2013; Faber et al., 2014).

In summary, other mechanisms besides melting may produce amorphous material in fault rock. Some of these mechanisms can be clearly linked to seismic slip, while others may not be related to deformation. As little is known about the characteristics of amorphous silicates in geologic environments, it may be impossible to tell these materials apart. The reports of amorphous material are rare, because it typically comprises a very small fraction of the rock, and is only detectible by specific and careful X-ray diffraction analyses using internal standards, or by transmission electron microscopy (TEM), neither of which is routine in fault rock studies. In addition, the production of amorphous and cryptocrystalline material from thermal breakdown of other minerals during seismic slip poses serious prob- 
lems for preservation in the rock record. As has been long recognized in pseudotachylyte studies, silicate amorphous material is not stable and will tend to crystallize at temperatures above $\sim 100^{\circ} \mathrm{C}$. Therefore, the crystallized remnants may be the only record of coseismic amorphization or melting (Wenk, 1978; Allen, 1979, Kuo et al., 2009; Kirkpatrick and Rowe, 2013).

\section{Diagnostic criteria for fast rupture velocity}

The stress fields around crack tips have been a constant topic of study for over a century (Inglis, 1913, Griffith, 1921). The near-tip stress field controls crack propagation and the formation of secondary structures around faults (Pollard and Segall, 1987). For geological applications, crack-tip stresses, strains, and displacements may be evaluated quantitatively in a quasi-static framework, in which the stress and displacement fields around a crack are derived by solving the static equations of motion (subject to appropriate constitutive, compatibility, and boundary conditions, e.g. Pollard and Segall, 1987; Crider et al., 1996). This approach can be used to predict where stresses will exceed rock strength, leading to failure. The assumption of quasi-static conditions during deformation implies that inertial forces are negligible, and as such, are omitted from the equations of motion. However, as crack propagation velocity increases, particle accelerations and related inertial effects become significant, requiring evaluation of the dynamic problem (Freund, 1998).

As an example, Figure 6 shows several different normalized stress quantities (radial $\left(\sigma_{r r}\right)$, hoop $\left(\sigma_{\theta \theta}\right)$; shear $\left(\sigma_{r \theta}\right)$ and Coulomb $\left(\sigma_{c}\right)$ stresses) plotted in a polar coordinate system centered at the propagating tip of a right-lateral mode II semi-infinite crack moving at different rupture velocities $\left(v_{r}\right)$ expressed as a percentage of the shear wave speed $\left(c_{s}\right)$ (Freund, 1998). For all cases, the stress amplitudes increase significantly above the static case $\left(v_{r}=0\right)$ when $v_{r}>0.6 c_{s}$, with the peak value of $\sigma_{1} / \sigma_{1}^{0}$ exceeding the static case by a factor of 5 at $v_{r} \approx 0.85 c_{s}$ (Figure $1 \mathrm{C}$ ).

At $v_{r}=0$, the hoop stress reaches a minimum (compression) and maximum (tension) at $\pm 70.5^{\circ}$ respectively, the classic quasi-static explanation for the formation of solution seams and splay cracks (Rispoli, 1981) (Figure 6). At $v_{r}=0.85 c_{s}$, however, the inclinations and magnitude of the maxima and minima of the hoop stress increase dramatically (to $\sim 100^{\circ}$ ) compared to the static case $\left(\sim 70^{\circ}\right.$, Figure $\left.1 \mathrm{C}, 6\right)$. This near tip field moves with the rupture, causing transient deformation in the vicinity of the rupture tip.

Because the magnitude and distributions of dynamic stress maxima and minima are fundamentally different than around the quasi-static crack, the 

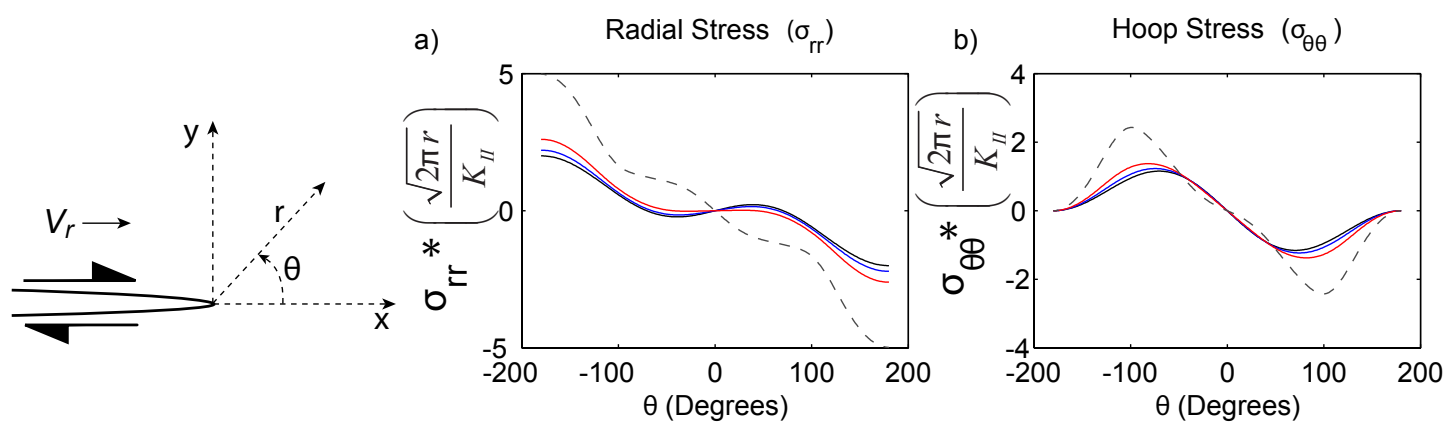

c)

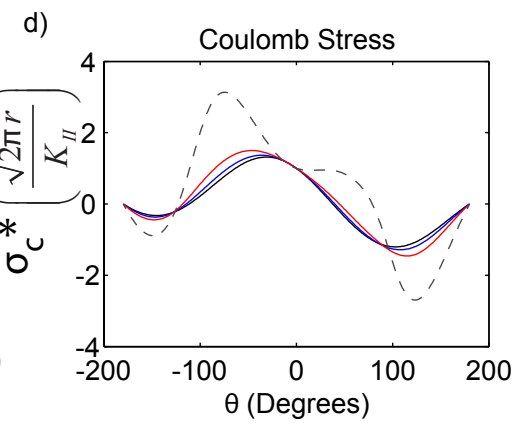

Figure 6: Normalized asymptotic crack tip stress fields (Freund, 1990 Broberg, 1999, Poliakov et al. 2002) for 4 different rupture velocities $\left(V_{r}\right)$ from 0 (the quasi-static case) to $85 \%$ of the shear wave speed $\left(C_{s}\right)$. All stress fields are normalized, where $K_{I} I$ is the mode II stress intensity factor. a) Radial stress, b) Hoop or Circumferential stress, c) Shear stress, and d) Coulomb stress $\left(\sigma_{c}=\sigma_{r \theta}+\mu * \sigma_{\theta \theta}\right)$ for $\mu=0.75$. Note that there is a slight shift in orientation and major increase in magnitude of the hoop stress with $V_{r}$ approaching $C_{s}$. The shear stress and coulomb stress have two maxima for values of $V_{r}$ approching $C_{s}$ as opposed to a single maximum for lower rupture velocities. 
permanent deformation associated with fast shear rupture has the potential to be distinguished from slow moving ruptures based on the geometry and distribution of secondary structures along exhumed faults. In other words, by considering transient stress, strain, and strain rate fields associated with dynamically propagating shear ruptures, fault structures previously elusive within the context of quasi-static fault mechanics can be used to identify earthquakes in the rock record and unlock additional information about the rupture process.

\subsection{Clearly Earthquake-Related}

\subsubsection{Injection Veins}

Experimental and theoretical studies have explored the generation of off-fault brittle deformation related to propagating earthquake ruptures. In general, these studies predict extensive failure both adjacent to, and far from, propagating rupture tips. For example, tensile cracks were observed to grow from rupture tips in experiments on cohesive faults in Homalite100; the orientation of these cracks is controlled by the rupture velocity $v_{r}$ (Samudrala et al. 2002). Models testing the combined influence of the pre-rupture stress state and velocity of shear ruptures show that extensive off-fault compressive and tensile failure are possible under some conditions (Poliakov et al., 2002; Rice et al., 2005). Surface cracking in regions around earthquake epicenters may even be explained by the off-fault stressing caused by transient stress fields associated with dynamic rupture (Bhat et al., 2007; $\mathrm{Xu}$ et al. 2006, Loveless et al., 2011).

Field evidence of off-fault tensile fractures similar to those produced in experiments (Samudrala et al., 2002; Griffith et al., 2009) has been reported in several faults, notably the Gole Larghe Fault Zone in the Italian Alps (Di Toro et al. 2005). Evenly-spaced tensile cracks filled with pseudotachylyte (injection veins) demonstrate that the cracks opened coseismically (e.g. Figure $7 \mathrm{~A}$ ), and these have been described in isotropic and foliated host rocks (Rowe et al., 2012b; Swanson, 2005). These injection veins are typically oriented at a high angle to the fault surface $\left(>70^{\circ}\right)$, and occur preferentially on one side of the fault (e.g. Figure $7 \mathrm{~A}, \mathrm{~B}$ ). The tendency of the tensile fractures to concentrate on one side of the fault is readily explained by the asymmetry of the normal stress components around a propagating dynamic rupture tip (Figure 1 $\mathrm{C}$; 6). Using a velocity-weakening mode II model of earthquake rupture, Ngo et al. (2012) showed for a prestress state typical of large, strike slip earthquakes, that injection veins associated with this mechanism should form exclusively at large inclination angles $\left(>70^{\circ}\right)$ to the main 

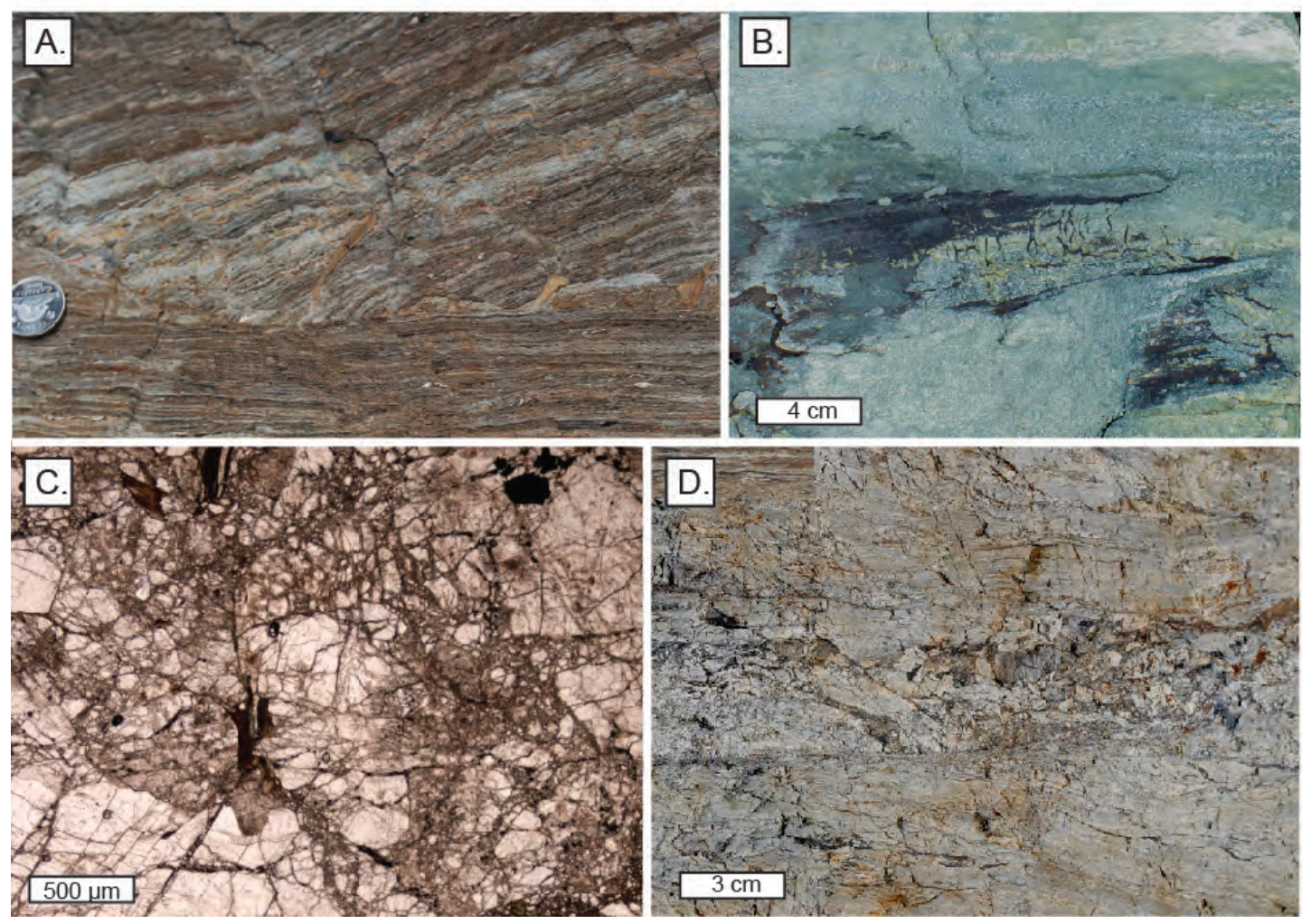

Figure 7: A: Detail of a pseudotachylyte fault vein with evenly spaced injection veins, Norumbega System, Fort Foster, Maine. See Swanson (2006a) for details. B: Eroded surface of a pseudotachylyte fault vein (purple patches) showing the footprint of injection veins extending down into the greenstone wallrock, showing regular length and spacing in the slip direction. Photographed in float near the Moonlight Fault, Wanaka, New Zealand. C: Pulverized granite from the southern San Andreas fault (locality described by Wechsler et al. (2011), photomicrograph provided by Tom M. Mitchell.) D: Brecciated zone between two pseudotachylyte veins is partially filled with pseudotachylyte, indicating brecciation of the wallrock was coseismic. Norumbega Shear Zone, central Maine. 
fault plane. At depths of $>5 \mathrm{~km}$, tensile stresses can overcome confining stresses only at rupture velocities approaching $c_{s}$ (Ngo et al., 2012).

"Splay" or "wing" cracks form as mode I fractures or veins due to static stress perturbations at the tips of faults (Rispoli, 1981; Segall and Pollard, 1983 Willemse and Pollard, 1998, Mutlu and Pollard, 2008). Their angle to the fault can vary depending on the distribution of tractions near the fault tip (predicted by the quasi-static formulation described above), and they are usually identified around bends or tips of faults. Injection veins formed due to the dynamic stressing described above have several characteristics which distinguish them from wing cracks, including: (1) the concentration in arrays on one side of the fault, (2) forming angles of $>70^{\circ}$ to the fault surface, (3) planar geometry with consistent orientation, and (4) occurrence in spaced sets, not obviously linked to a local irregularity in the fault surface, nor concentrated at the fault terminations (Figure $7 \mathrm{~A}, \mathrm{~B}$ Di Toro et al. 2005 Ngo et al., 2012). While pseudotachylyte injection veins are clearly a product of seismic rupture, the formation mechanism described above would imply that other types of off-fault veins and/or fractures may also form in a similar fashion in the absence of pseudotachylyte. For example, two types of arrays of high-angle tensile fractures distributed along faults (feather fractures, Cloos (1932); and T Group fractures, Petit (1987)), have been interpreted as sense-of-shear indicators on the main fault, although the growth mechanisms are undefined.

\subsubsection{Pulverization}

Pulverized rock, or "powdered rock" formed without grinding or milling, was described in the San Andreas fault (Brune, 2001), and in induced earthquakes and rock bursts in South African mines (Stewart et al., 2001). Pulverized rock is clearly distinct from fault gouge, as the mineral fragments are not sheared relative to one another, suggesting that the rock has been fragmented without any shear strain (Figure $7 \mathrm{C}$ ). Particle size distribution (PSD) of suspected pulverized rock shows patterns distinct from typical fault gouge (Chester et al., 2005; Wilson et al., 2005). The width of the pulverized damage zone may be extended to several meters from the fault due to high strain rates along mach fronts of supershear ruptures (Doan and Billi, 2011; Yuan et al., 2011) or by the presence of pre-existing damage that allows pulverization at lower peak stress during subsequent high strain rate loading (Doan and dHour, 2012). Reches and Dewers (2005) related the pulverization process to rapid volume changes caused by stress and strain-rate spikes at the tip of propagating dynamic ruptures (e.g. Figure 1 C). Their models predict pulverization in a thin (millimetric) zone around the sliding 
surface, but field observations have reported pulverized zones 100s of meters wide in asymmetric corridors along active faults (Dor et al., 2006a; Mitchell et al. 2011; Rempe et al., 2013). The wide zones of pulverized rock occur in stiff plutonic rocks (granitoids) where they are juxtaposed against weaker rocks on the other side of the fault (Dor et al., 2006b). This pattern, and the extreme thickness of the pulverized zone, may be an effect of supershear rupture $\left(v_{r}>c_{s}\right)$ which under certain conditions produces wide "mach fronts" of extreme transient stress around the dynamic rupture tip (Ben-Zion and Andrews, 1998; Ampuero and Ben-Zion, 2008; Passelègue et al., 2013).

A series of experimental investigations of the pulverization process in rocks have utilized the Split Hopkinson Pressure Bar to achieve the necessary bulk strain rates to mimic co-seismic rupture conditions (Xia et al., 2008, Doan and Gary, 2009; Doan and Billi, 2011; Doan and dHour, 2012). These experiments revealed that dynamic pulverization is characterized by small strain after which original rock fabrics are still recognizable through fracture networks, an observation consistent with micro structural observations of pulverized damage zone rocks (Mitchell et al., 2011). Pulverization, at least in granitoid rocks, occurs above a critical strain rate threshold, and this threshold increases with increasing confining pressure (Yuan et al., 2011). At high strain rates, the transition from discrete fracture to pulverization is governed by the rate sensitivity of fracture toughness, adding evidence that rock pulverization is a true signature of high strain rate deformation that can only be achieved during earthquake rupture or extraterrestrial impacts (Bhat et al. 2012).

\subsection{Potentially-Earthquake Related}

Near an earthquake rupture tip, rocks experience extreme fluctuations in stress, strain rate, and, in at least some cases, temperature. Similar transient, extreme conditions are also associated with extraterrestrial impact events (French, 1998; Sagy et al., 2002); therefore impact structures are useful natural analogs for transient earthquake deformation in rocks. Several structures commonly observed at impact sites and associated with shock deformation have been proposed as diagnostic of earthquake-like deformation conditions, although it is not clear that stress, strain rate, or temperature conditions achieved during earthquakes are sufficient to replicate such features. The challenge of interpreting the dynamic stresses and strains, or scaling between impact conditions and seismic conditions, warrants future work. 


\subsubsection{Branching Fractures}

Shatter cones are semi-conical groups of hierarchical, branching striated fractures which have been associated with dynamic tensile fracture propagation at the trailing edge of shock waves (Dietz, 1959). The inferred mechanism for shatter cone formation is fracture tip instability as mode I rupture velocity approaches the Rayleigh wave speed (Gash, 1971; Sagy et al., 2002). This has led some to suggest that branching fractures may present evidence of dynamic loading conditions vis à vis seismic deformation on nearby faults (e.g. Figure 7D, Melosh et al., 2014). While branching during mode I fracture growth likely implies dynamic crack propagation, it can also be induced by quasi-static loading (Sagy et al., 2001). Therefore, branching mode I fractures may be suggestive of earthquake deformation, but not definitive.

\subsubsection{Planar Deformation Features}

Planar deformation features (PDFs) in quartz, also known as shock lamellae, are thin zones of quartz with low dislocation density, separated by thin amorphous domains (e.g., Carter et al., 1990). Single or multiple sets of PDFs are common features associated with meteorite impact sites, and have been shown experimentally to be associated with shock deformation conditions (transient stresses exceeding $\sim 10 \mathrm{GPa}$ ) (Carter, 1965; Carter et al. 1990, French, 1998). While these are larger stresses than typically expected during earthquakes (Reches and Dewers, 2005), experiments have suggested that PDFs can form at smaller stresses at elevated temperatures (Reimold et al. 1988). Based on these observations, Carter et al. (1990) suggested that PDFs may form during explosive volcanic events. Subsequent experiments designed to test whether shock-induced PDFs are identical to those formed during tectonic deformation show that they are distinguishable, because tectonic features are slightly curved along subgrain boundaries formed by dislocation glide and climb, while shock-induced PDFs are perfectly planar and have much sharper edges (Vernooij and Langenhorst, 2005; Hamers and Drury, 2011).

Mechanical Dauphiné twinning in quartz is well-documented in rocks recovered from impact structures (Trepmann and Spray, 2005, Wenk et al. 2005) and has been reported in association with seismic pseudotachylytes (Wenk et al., 2011). The formation of Dauphiné twins is associated with large differential stress (Tullis, 1970), but they are also common in natural samples deformed at elevated temperatures (Trepmann and Stöckhert, 2003). They probably record high stress magnitudes, but similar to PDFs, the exact magnitude of the stress required to form them is probably much 
lower at higher temperatures. So although Dauphiné twins likely form during earthquakes, the association may not be exclusive.

\subsubsection{Feather Features}

Some quartz grains deformed during impacts also display intriguing structures growing from planar shear fractures which resemble the tensile microcracks described in Section 4.1.1, on a smaller scale. These "feather features" (French et al., 2004; Poelchau and Kenkmann, 2011) have been inferred to form during relatively low pressure shock deformation and have been proposed as a criterion for recognizing impact-related deformation in rocks which are distal from the impact site. Feather features have lengths on the order of $10-100 \mu \mathrm{m}$ with spacings on the order of $15 \mu \mathrm{m}$ and form at systematic angles along some preferred planes of the quartz lattice (Poelchau and Kenkmann, 2011). Based on subparallelism with maximum principal stress during shock recovery experiments, Poelchau and Kenkmann (2011) inferred that feather features are controlled by the direction of the remote principal stresses; however, examination of their data also show that the spatial distribution and inclination of feather features are consistent with growth at the tips of micro-shear ruptures along the planar fractures from which the feather features emanate. To the best of our knowledge, feather features have not been reported in fault rocks; however, given the fact that PDFs have been recognized in fault gouge, it is not unlikely that feather features should form if they are indeed controlled by fast strain rate and large peak stress conditions.

While the "extreme" stress magnitudes expected at earthquake rupture tips (on order 5 GPa, Reches and Dewers, 2005) are on the low end of transient stresses associated with impact structures, there is enough overlap, and enough preliminary observations in the literature, to motivate the exploration of near-tip microstructures for impact-like features.

\section{Discussion}

\subsection{Interaction between weakening mechanisms}

The confident association of pseudotachylyte with seismic slip has enabled the use of pseudotachylytes to understand seismic rupture parameters, particularly in the 15 years since Cowan (1999) (e.g. Allen, 2005; Di Toro et al., 2005: Swanson, 2006a; Nielsen et al., 2010). These efforts coincided with, and benefited from, the emergence of specialized experimental apparatus capable of simulating the stress and slip rate conditions of earthquakes. Textural, microstructural, and chemical signatures of earthquakes can now 
be assessed by comparison to experimental products where stress, slip rate, and chemical conditions are known (for a review, see Niemeijer et al., 2012, and references therein). Discovery of subtle chemical signatures of heating in natural faults, and calibration through laboratory heating experiments and constraints on kinetics of reactions at high heating rates, has provided other lines of evidence for past seismic slip (O'Hara, 2004; Ishikawa et al., 2008, Polissar et al., 2011). In Table 1, we summarize the temperature sensitivity of the variety of thermal indicators that have been recently developed to measure fault heating associated with earthquake slip. In some lithologies, and with detailed understanding of the structural context, it is now possible to identify evidence of coseismic shear heating of almost any magnitude. Thus, we are no longer reliant on pseudotachylyte as the only indicator of earthquakes in the rock record.

Of course, the temperature rise in deforming rock is related to the thickness of the deforming zone. Frictional heating proxies are effective at detecting localized fast slip at high rates of shear strain in a narrow slip surface. They are not effective at detecting distributed fast slip at low shear strain rates in a wide slipping zone. Likewise, models for transient high stresses associated with dynamic ruptures also assume negligibly thin slipping surfaces. Thus, the possibility of seismic slip across thick faults, as suggested by occasional reports of thick fluidized gouge zones (Viola et al., 2006; Rowe et al., 2011, 2012a), cannot be confirmed by comparison to currently available temperature proxies or dynamic rupture models.

As the study of field indicators of fast rupture is relatively new compared to studies of fast slip, this area has a high potential for future advances. The characteristic features which record fast rupture propagation and associated extreme stress transients are likely to occur in combination with each other, or alongside features recording fast slip. For example, coseismic rock bursts in a South African gold mine produced pulverized "rock flour" as well as fracture patterns characteristic of dynamic fracturing (Stewart et al., 2001), and possible planar deformation features (Olgaard and Brace, 1983), showing that multiple lines of evidence for earthquakes may be found together in the absence of evidence for fast slip. The effects of rupture tip damage may also be important for the understanding of fault rock evolution. Fault gouge is traditionally thought to form by fracturing and rounding of larger particles during grinding and comminution (Engelder, 1974, Sammis et al., 1986), but successful pulverization experiments suggest that dynamic fracturing may play an important role (Mitchell et al., 2013). Experiments on the initiation and then slip of fractures in dacite showed that the finest $(<10 \mu \mathrm{m})$ "gouge" particles are produced during the initial fracture-forming rupture, 
and do not increase in number during continued sliding, even while additional coarse gouge is produced from wear of the wall rock (Kennedy and Russell, 2012). Interestingly, the number of very fine $(<10 \mu m)$ particles produced during fracturing scaled with stress drop.

We have discussed earthquake signatures in isolation, but it is important to acknowledge that multiple frictional weakening mechanisms act in concert, and develop feedbacks with one another, during seismic rupture. As field geologists, we observe fault rocks which are the final product of multiple processes acting during one or more slip events. During the nucleation stage, in which slip is too small to result in broad temperature rise, initial weakening in most fault materials is thought to be controlled by flash heating of asperity contacts (e.g. Rice, 2006, Beeler et al., 2008; Goldsby and Tullis, 2011; Chang et al., 2012). However, the duration of flash heating corresponds to the time it takes for a fault to slip only a few microns. Thus, modification of pulverized rock during acceleration, slip, and deceleration likely overprints any signatures of flash heating in natural or experimental fault rocks. Pulverization dramatically increases rock surface area, which facilitates the activity of frictional weakening mechanisms (e.g. fluidization, melting, decarbonation or devolatilization, etc.). The final deformed rock may show features indicative of one or more of these mechanisms, but the evidence of one process may overprint earlier materials. Therefore, the identification of one weakening mechanism in the rock record does not preclude the importance of others, nor does it demonstrate that the identified mechanism was the primary process leading to earthquake instability.

\subsection{Comparing experiments to natural faults}

Many of the features described above have been reproduced in the laboratory, in high-velocity rotary shear experiments or in other high strain rate configurations. Scaling of parameters such as slip rate, acceleration, and normal stress, from nature to the laboratory, is not a trivial endeavor. For example, pronounced weakening is observed in all rocks sheared at slip rates of $\geq 10^{-2} \mathrm{~m} / \mathrm{s}$, which corresponds to earthquake nucleation conditions at low (laboratory) normal stresses. Weakening occurs at slower speeds and smaller slips at higher normal stresses (Di Toro et al., 2011), and localization associated with thermally-activated weakening mechanisms is self-perpetuating (Platt et al., 2014). Therefore, laboratory investigations of slip weakening (by any mechanism) likely over-estimate the slip rate required for activation of these mechanisms at depth.

Similarly, it is essential to discriminate between investigation of the stability conditions favorable for slip nucleation (e.g. "velocity-weakening") and 
conditions on a natural rupture surface. Natural fault ruptures are heterogeneous and include patches (asperities) that may be strong and/or velocitystrengthening, but still slip at fast slip rates, driven by rupture propagation (Faulkner et al., 2011; Noda and Lapusta, 2013). Spatial and temporal variability in moment release is required to explain the observations of low average stress drop during earthquakes, in light of complete stress drop observed in some velocity-weakening laboratory experiments (Scholz and Aviles, 1986 , Bouchon, 1997). If these fault patches were exhumed and found in outcrop, they would show evidence for fast slip, but may not display characteristics consistent with rupture initiation. We suggest that the criterion for labeling a geologic weakening reaction as "seismic" should not be that it only occurs at the earthquake average slip rate $(\sim 1 \mathrm{~m} / \mathrm{s})$, but rather that it is unique to conditions characteristic of earthquakes (slip rates $<10^{-4}-10 \mathrm{~m} / \mathrm{s}$ ), and does not occur during slow slip events $\left(\leq 10^{-9}-10^{-6} \mathrm{~m} / \mathrm{s}\right)$. Since slip rates $\sim 10^{-4} \mathrm{~m} / \mathrm{s}$ only occur during earthquakes (Figure 2 ), experiments at $10^{-4} \mathrm{~m} / \mathrm{s}$ cannot be used to simulate "aseismic" deformation conditions.

Other parameters, such as acceleration, may also be important. Pulverization at the leading tip of propagating ruptures is associated with fast particle accelerations resulting in enormous strain rates near the earthquake rupture tip. This pulverization leads to the production of powder consisting of nano particles, inferred to be an important weakening process (Ohnaka, 2003 Sone and Shimamoto, 2009; Chang et al., 2012). Peak accelerations precede peak slip velocities, so any weakening mechanism directly related to acceleration could contribute significantly to the weakening process and modify the fault rock properties relevant to heat-driven weakening. For example, the activation of weakening mechanisms such as thermal pressurization relies on temperature, expansivity, compressibility, dilation, pressure gradients and transient permeability, all of which are coupled in some way with slip rate and acceleration (Sibson, 1973, Mase and Smith, 1987). Since all of these factors must be scaled from laboratory to natural conditions, the prescription of a single slip rate criterion for an earthquake-like experiment is probably inappropriate.

With some exceptions (e.g. Yuan and Prakash, 2008; Proctor et al., 2014, Pec et al., 2012a; Auzende et al., 2015), the majority of the earthquake signatures discussed in this paper have been studied in high velocity experiments at shallow crustal conditions (room temperature; normal stress equivalent to $<3-5 \mathrm{~km}$ depth). Experiments conducted at low pressures and high slip velocity can only be directly compared to faults from shallow depths, typically shallower than the depths of earthquake nucleation and significant moment release (Sibson, 1982). Comparisons between experiments 
and fault products exhumed from greater depths are typically conducted through semi-empirical scaling exercises (e.g. Brantut et al., 2008; Di Toro et al., 2011). Our inability (as yet) to reproduce seismic conditions in the laboratory at more typical earthquake nucleation depths $(\sim 5-35 \mathrm{~km}$, depending on tectonic setting) therefore limits our ability to effectively use experimental insights to interpret geologic observations to learn about the earthquake rupture process.

The assumptions made in relating experimental results to realistic conditions have strongly affected the interpretations of geologic observations in natural faults. It is essential to identify these assumptions and continually review their validity. Below, we review common assumptions implicit in the selection of experimental conditions and materials that we feel are worthy of reconsideration, and speculate on the possible effects of these assumptions on our understanding of the rock record of seismicity.

\subsubsection{Materials for friction experiments}

The candidate lithologies forming the wall rocks of faults in the seismogenic zone can be inferred, based on the composition of the crust and upper mantle, and the pressure/temperature conditions at depth (e.g. Peacock, 1996, Moore et al., 2007). Fault rock differs from wall rock lithology in cohesion, grain size, porosity, and mineralogy, and these differences are responsible for the rheological contrasts that accommodate and localize slip on faults. For example, gouge formed at $\sim 10 \mathrm{~km}$ depth in a typical granite-hosted fault at a typical geothermal gradient of about $25^{\circ} \mathrm{C} / \mathrm{km}$ would form by brittle deformation of quartz and feldspar, and by hydrothermal alteration of feldspar and micas to form clay minerals (Figure 5A). Due to the strong cleavage of feldspar, grain size reduction is more pronounced in feldspar than in quartz (Evans, 1988, Rawling and Goodwin, 2003; Heilbronner and Keulen, 2006, Keulen et al., 2007). If hydrothermal alteration is extensive, feldspars and primary hydrous minerals will be completely replaced by low-temperature clays, and the gouge will be composed only of quartz, clays, and metallic oxides. The clay gouge is weaker than fractured granite, encouraging continued localization. Crushing and sieving granite and other rocks is a common practice for creating artificial gouge for experiments, but it does not produce a naturalistic gouge. Natural samples introduce more complexity to experiments, but have been successfully studied (e.g. Logan et al., 1981; Morrow et al., 1982; Chester and Logan, 1986 ; Numelin et al., 2007; Mizoguchi et al., 2007; Brantut et al., 2008; Collettini et al., 2009; Verberne et al., 2010; Ikari et al., 2015). Although the use of standard rocks and artificial fault gouge aid in the standardization of labo- 
ratory practices and elucidate general relationships, it would be encouraging to see more future collaboration between field geologists and experimentalists to design experiments that better reflect natural gouges observed on real faults. Since precise mineralogy, grain shape, and grain size distribution are significant in controlling shear behavior, these attributes should be well-characterized in both natural and artificial gouges to enable assessment of the validity of comparisons (e.g. Solum et al., 2003; Sulem et al., 2004; Anthony and Marone, 2005, Abe and Mair, 2009; Collettini et al., 2009. Wenk et al., 2010).

Additionally, tests of the properties of minerals at conditions where they would not exist in the earth do little to elucidate the properties of faults. Phase changes at different pressure/temperature conditions, and the related production or consumption of pore fluids, are essential for controlling the properties of faults at depth (Peacock and Wang, 1999; Currie et al., 2002, Fagereng and Diener, 2011). For example, testing the properties of smectite gouge at temperatures above the stability range of smectite clay is probably not useful for understanding conditions on faults except during temperature spikes too rapid for equilibrium phases to develop. The experimentally observed properties of smectite clay are most useful for understanding faults at temperatures below $\sim 100-125^{\circ} \mathrm{C}$ (i.e. the upper limit of smectite stability, Moore and Saffer, 2001), which would correspond to depths of less than $\sim 5 \mathrm{~km}$ in average continental crust, shallower than the locking depth on the San Andreas and the depth of nucleation of most earthquakes (Saffer and Marone, 2003; Tembe et al., 2009; Lockner et al., 2011). At temperatures characteristic of the seismogenic zone $\left(150-350^{\circ} \mathrm{C}\right.$; Sibson, 1982 ; Hyndman et al., 1997), smectite group clays are replaced by illite and chlorite, and additional alteration minerals are common (e.g. Schleicher et al., 2012). Thus, friction tests on these minerals, at appropriate pressure/temperature conditions, are potentially more illuminating of the behavior of faults during rupture nucleation and propagation. Overcoming the challenges in controlling temperature, fluid pressure and composition, and large stress, combined with the complicated mineralogy of the seismogenic zone, are areas of active research.

At convergent margins, subducting rocks are subject to prograde metamorphism while actively deforming in the plate boundary shear zone. In metasediments and metabasalts, the most abundant rocks in the seismogenic zone are at greenschist to lower blueschist facies (Moore et al., 2007). Epidote, actinolite, albite, illite, and chlorite dominate the mineralogy of these rocks, but there have been few friction experiments using appropriate samples (recent progress includes Saffer and Marone, 2003, Ikari et al., 2009 , 
Carpenter et al., 2011; Niemeijer and Vissers, 2014, Den Hartog et al., 2014; Sawai et al., 2014).

Experimental friction and rheology studies can only be used to interpret natural fault rocks if microstructural studies are performed on experimental samples before and after deformation. The fingerprinting of structural evidence for different modes of deformation, or transitions in rheology, is the key to applying experimental insights to field studies (e.g. Logan et al., 1992, Niemeijer and Spiers, 2005, Collettini et al., 2009, French et al., 2014). We encourage experimentalists to publish descriptive data on their samples before and after deformation, and to work with field geologists who can provide natural samples of gouge and cataclasite from well-documented settings, and make apples-to-apples comparisons between natural and experimental microstructures.

\subsection{Influential fault studies}

A broad range of field studies of exhumed faults have contributed to our knowledge of fault deformation processes, but a few examples stand out for their contributions in establishing the paradigms that spread beyond the structural geology community and inform seismology, numerical modeling, and experiments. Field observations help us to constrain fault geometry and material properties (Figure 8). However, it is rare that the spatial scale of field observations overlaps with the crustal scale of seismic or geodetic observations, limiting our ability to make direct comparisons. Exposures of modern and ancient faults are obscured in most climates by soil and vegetation, buried or destroyed by land use practices, or by sedimentary deposits. Fault core exposures of high quality and extent are therefore concentrated in remote regions where the arid climate prohibits soil development (e.g. the Atacama Fault, (Mitchell and Faulkner, 2009); the Naukluft Thrust (Viola et al., 2006), and the Pofadder shear zone (Melosh et al., 2014), Figure 83. ), or where recent uplift and fast erosion has exposed larger areas of fresh rock (e.g. faults of the Sierra Nevada Batholith, Kirkpatrick et al. (2008) and Griffith et al. (2008) and the Pasagshak Point thrust, Figure 8C (Rowe et al., 2005)). Even where exposure is exceptional, fault exposures tend to be preferentially weathered and altered, and the preservation of slip-related structures can be degraded.

One notable example is the Punchbowl fault, an extinct strand of the San Andreas in southern California with about $40 \mathrm{~km}$ strike-slip offset. Several landmark studies documented in detail the structure of the fault core, consisting of a sharp principal slip zone, surrounding gouge zones derived from the respective wall rocks, and a fractured damage zone (Chester and Logan, 

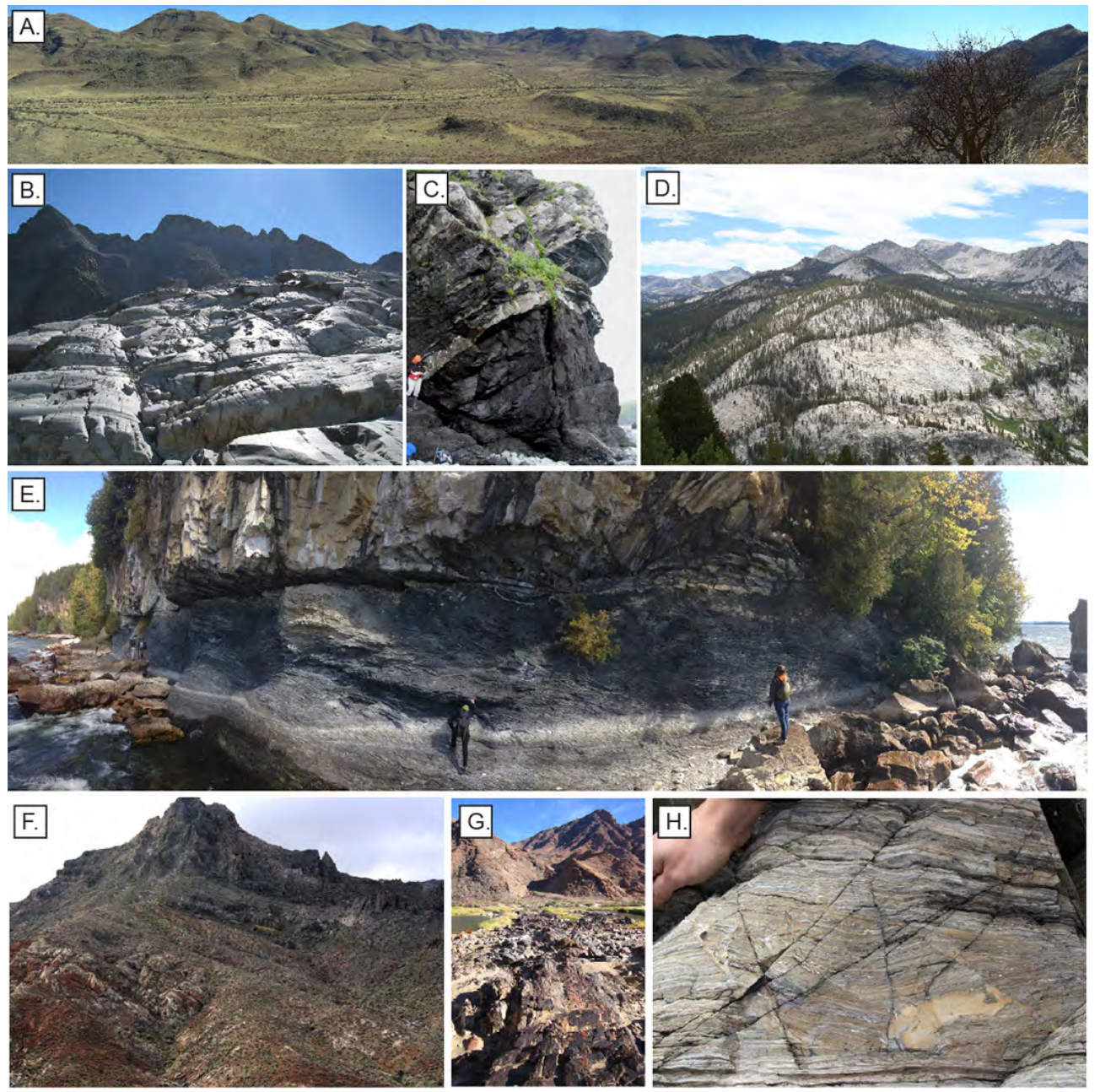

Figure 8: Examples of extraordinary outcrop exposures of paleoseismic fault zones. A: Regionally extensive continuously exposed plane of the Naukuft Thrust, Namib-Naukluft National Park, central Namibia. Thrust is prominent line visible cutting hills from upper left to middle right, visible due to extremely thin soil cover. Panoramic photo by Åke Fagereng. B: Recently deglaciated surface of the Adamello Pluton exposes reactivated joints and pseudotachylyte faults of the Gole Larghe fault zone, Italy . C: Wave-cut outcrop of a discrete fault surface, exposed due to rapid tectonic uplift and rapid erosion. Pasagshak Point thrust, Kodiak Island, Alaska. F. Meneghini for scale. D: Sparse soil and vegetation in the high Sierra Nevada gives a large area of exposure of the Bear Creek Fault Zone, California. E: Distorted panorama of structural geology students visiting the Champlain Thrust, outcropping along Lake Champlain in Burlington, Vermont. Seasonal erosion refreshes the outcrop and removes debris every year. Photo by Nick Harrichhausen. F: Muddy Mountain Thrust, Nevada - well exposed over large areas by the combination of dry climate and recent uplift. G: Pofadder Shear Zone, photo taken from South Africa along mylonites across the Orange River into Namibia. Well exposed by due to hyperarid climate and extremely old surface age at 100 rates of erosion. Cows at center left for scale. Photo by Louis Smit. H: Detail of pseudotachylyte pooling between two fault surfaces, Norumbega System, Fort Foster, Maine. Excellent outcrop preservation and slight relief due to differential weathering of foliation in the host rock ultramylonites reveal sub-millimetric details of the paleo-rupture surface to the naked eye. Without the weathered surface, both ultramylonite and pseudotachylyte are glassy and black in appearance, and very difficult to distinguish. See Swanson (2006b) for details. 
1986, 1987; Schulz and Evans, 1998, 2000). From these studies, a general model for fault structure was developed that has had a significant influence on the development of theoretical modes for seismic slip (e.g. Rice, 2006). The description and explanation of foliated cataclasites in the Punchbowl fault brought major changes to our understanding of fault rock evolution (Chester and Logan, 1987; Chester and Chester, 1998). The particle size distribution of the slip surfaces was measured and related to fracture energy during earthquakes (Wilson et al., 2003; Chester et al., 2005). The outcrops of the Punchbowl fault have been used to study along-strike variations in fault and damage zone structure (Schulz and Evans, 1998), the mineralogy of fault gouge (Solum et al. 2003), and the effects of faulting on organic maturity (Polissar et al. 2011). The contributions of Punchbowl fault studies to the general understanding of fault rocks, architecture, and mineralogy has been profound.

Another example is the Gole Larghe fault zone in the Italian Alps (Figure 8B; Di Toro and Pennacchioni, 2004; Di Toro et al., 2009). Numerous studies using the Gole Larghe fault zone as a natural laboratory have resulted in significant contributions to both earthquake mechanics and structural geology. Identification of evenly spaced pseudotachylyte injection veins elucidated asymmetric tensile stress at rupture tips (Di Toro et al., 2005). Integration of field observations with specially-designed high velocity friction experiments allowed for documentation of melt lubrication for the first time (Di Toro et al., 2006a b). Roughness of frictionally melted fault surfaces were measured in two dimensions (Nielsen et al., 2010; Bistacchi et al., 2011) and in three (Resor et al., 2014), and Griffith et al. (2010) modeled the effects of the roughness on off-fault damage. Other studies have demonstrated the roles of cataclasis, hydration, and healing on pseudotachylyte genesis (Mittempergher et al., 2009) and the earthquake energy budget (Pittarello et al. 2008). As the Gole Larghe pseudotachylytes occur along pre-existing cooling joints in the Adamelo pluton, the geometry of the faults is largely inherited (Di Toro and Pennacchioni, 2004, Pennacchioni, 2005). The structural inheritance evident in this fault zone is consistent with observations of some other fault zones developed at seismogenic depths (e.g. Crider, accepted, and references therein).

At both the Punchbowl and Gole Larghe fault localities, studies spread over many years contributed first-order qualitative and quantitative information about faults, and also produced representative idealized models and interpretations which linked structural and chemical observations to earthquake mechanics (Chester et al., 1993, Smith et al., 2013a). With this foundation, numerical modelers, seismologists, and geophysicists have been 
able to incorporate the structural observations into their understanding of faults. Very few faults have been described and interpreted to the same level of detail or in a similarly accessible manner. These localities were selected by the original authors for detailed study due to preservation, accessibility, and quality of exposure. Both localities offer individual snapshots of faults from particular depths and particular points in their evolution. One critical question that needs to be addressed, however, is whether or not these two classic examples are representative archetypes of seismic faults at their respective depths of exhumation. Is it worth pursuing parallel questions at other localities, to elucidate the variety and range of fault structures in the rock record?

Although examples of different fault architecture are abundant, they have not had the same penetration outside the structural geology community. For example, faults with multiple anastomosing principal slip zones, interpreted as sharing slip between multiple surfaces, have been described in the field (Chester and Logan, 1986, Caine et al., 1996, Faulkner et al., 2003 Rowe and Backeberg, 2011), but rarely attempted in numerical models. Some reports suggest that multiple slip surfaces may be active in parallel during a single rupture (Allen, 2005; Swanson, 2005; Heesakkers et al., 2011), These sources of complexity have received little attention in terms of their mechanical implications for earthquake rupture.

Likewise, the architecture of subduction thrust faults has only been synthesized on the broadest scale (e.g. Fisher and Byrne, 1987). Isolated examples of detailed studies in accretionary wedges have identified faults with single sharp discrete cores (Kondo et al., 2005) and thick brittle shear zones built by successive migration of deformation (Wakabayashi and Rowe, 2015). Studies of the Pasagshak Point thrust have shown evidence for multiple anastomosing strands which share slip over a structural width of 100 s meters, with repeated seismic rupture through the different strands (Figure 8C; Rowe et al., 2005; Meneghini et al., 2010; Rowe et al., 2011). The amazing along-strike exposure at this locality $(\sim 2.2 \mathrm{~km}$ continuous outcrop, total of $\sim 5 \mathrm{~km}$ ) is sufficient to reveal considerable heterogeneity in both wall rock damage and fault core structure. This scale of heterogeneity may be large enough to significantly affect rupture propagation, but is almost never observable in field studies on ancient exhumed faults.

What biases are field structural geologists inadvertently bringing to the rock record through outcrop selection and field practice? Geologists select well-exposed, sharp fault cores to study, particularly because structural localization is thought to correspond to seismic slip (e.g. Rice, 2006). Indicators of frictional heating (Table 1) are strongly dependent on slip zone 
width and cannot be used to detect fast slip rates over a distributed slip zone. Thus, no field test exists to determine whether earthquake rupture might locally propagate through thick faults or thick patches on faults, although some very thick fluidized cataclasites seem to indicate this is locally possible (Rowe et al., 2011; Viola et al., 2006). Delocalized slip patches may help produce transient asperities during rupture and explain propagation rate variations in large earthquakes (e.g. Meng et al., 2011).

\section{Future perspectives}

Our understanding of the rock record of earthquakes has increased substantially in the past 15 years, with the development of new methods for detecting both frictional heating (as a proxy for fast slip) and fast rupture propagation. We are not reliant on pseudotachylyte alone as an indicator of ancient earthquakes. Despite the recent recognition of slow slip events with slip rates and rupture velocities falling between those of traditionally aseismic and earthquake slip events, most of these new criteria are exclusively indicative of earthquakes in the traditional seismological definition. We anticipate the identification of more criteria in the future, particularly related to transient fields associated with the earthquake rupture tip.

When it comes to generalizing our work, field geologists do not choose our model medium, geometry, or deformation conditions, nor do we have much control over the preservation and exposure of our outcrops. The advantage we gain is a contextual understanding of the complexities we observe in the field. The way we report these complexities affects the way that information is translated to researchers focused on modeling the physical and chemical processes that shape the structures we study. The example fault zones discussed above stand out not only in terms of excellent outcrop exposure, but in the success of the investigators in reducing their observations to a set of fundamental interpretations that formed the basis for constrainable problems.

Field observations may be our most reliable guide for scaling observations from laboratory experiments to nature. Because earthquake rupture and slow slip events are spatiotemporally complex, it is critical to consider outcrop observations of fault products within the context of the full range of fault slip behavior. It may be useful to begin to consider other portions of the source time function, in addition to slip and rupture velocities. This requires acknowledgement of the static pre-stress state, the nucleation, acceleration, deceleration and healing phases, as well as the potential for post-seismic slip. It also requires placing observations in the broader spatial 
context of the fault, and acknowledging that it will be a rare case when the outcrop or the borehole intersects the area of maximum slip or slip rate on the rupture surface.

Ongoing questions that are of immediate importance include:

1. What role, if any, does the generation of these earthquake signatures play in the weakening process? Does weakening actually precede the generation of the permanent deformation products preserved in the rock record?

2. Is there any aspect of the earthquake time function beyond slip and rupture velocity that is recognizable in the rock record?

3. How do results of idealized experiments scale to natural faults? Can differences in lithology, pressure, temperature, and strain rate between model and prototype by resolved by simple scaling exercises? Or is it instead necessary to increase the complexity in experiments and numerical models?

4. As earthquake geologists, what are the inherent biases that our work introduces to other parts of the earthquake community? Are our field areas representative prototypes for models? How generalizable are our conclusions based on specific field areas?

The past 15 years have shown that careful studies of faults, in the field and on the micro- to nanostructural scales, continue to uncover previously unknown fingerprints of seismic slip. These fingerprints not only preserve the rock record of earthquakes, but they also reveal the interactions between chemical reactions and mechanical deformation that contribute to coseismic weakening and healing of fault zones.

\section{Acknowledgements}

We thank Darrel Cowan and Phil Resor for collaborating with us on the 2013 GSA session that inspired this paper. We gratefully acknowledge useful discussions with, and suggestions from: Nils Backeberg, Naomi Barshi, Emily Brodsky, Frederick Chester, Kelian Dascher-Cousineau, Giulio Di Toro, Nick Harrichhausen, Tom Heaton, James Kirkpatrick, Tom Mitchell, Casey Moore, André Niemeijer, Pratigya Polissar, Heather Savage, and many other friends and colleagues, but these helpful folks are not to be held accountable for the opinions in this manuscript. We thank Åke Fagereng, Louis Smit, Tom Mitchell, and Nick Harrichhausen for use of their photographs in Figure 7 and 8. CDR was supported by the NSERC Discovery Grant Program and the Robert P. Wares Faculty Scholarship. WAG received 
Table 1: Frictional heating proxies for peak temperatures below melt temperature. Sources: ${ }^{1}$ Schleicher et al. (accepted), ${ }^{2}$ Kameda et al. (2011), $\sqrt[3]{\text { Evans et al. }}(2014)$, ${ }^{4}$ Ishikawa et al. (2008), ${ }^{5}$ Mishima et al. (2006), ${ }^{6}$ Collettini et al. (2013), 'Grim and Bradley (1940), ${ }^{8}$ Isambert et al. (2003), " ${ }^{9}$ McIntosh et al. (1990), ${ }^{14}$ Sheppard et al. (2015), ${ }^{11}$ Rabinowitz et al. (2014). Most or all of these reactions are Ahrrenius relationships where reaction progression depends upon time-temperature path, so time path has been roughly estimated based on heating rates on the order of $10 \mathrm{~s}-100 \mathrm{~s}^{\circ} \mathrm{C} / \mathrm{m}$.

\begin{tabular}{|c|c|c|}
\hline Peak temp. & Mineralogy & Indicators \\
\hline$\sim 250^{\circ} \mathrm{C}$ & Smectite clay & $\begin{array}{l}\text { Expulsion of interlayer water; resistance to re- } \\
\text { hydration }^{1}\end{array}$ \\
\hline$\sim 250^{\circ} \mathrm{C}$ & $\begin{array}{l}\text { Smectite/chlorite in- } \\
\text { terlayers, corrensite }\end{array}$ & Transformation of smectite to chlorite ${ }^{2}$ \\
\hline$\geq 300^{\circ} \mathrm{C}$ & Hematite fault veins & $\begin{array}{l}\text { Reduction iridescence of hematite to magnetite } \\
\text { transition }^{3}\end{array}$ \\
\hline$\geq 200-350^{\circ} \mathrm{C}$ & Any fault gouge & Trace element exchange (especially Li, Rb, Cs) ${ }^{4}$ \\
\hline$\sim 400^{\circ} \mathrm{C}$ & $\begin{array}{l}\text { Fe-bearing smectite } \\
\text { clay }\end{array}$ & $\begin{array}{l}\text { Breakdown of clay; formation of high magnetic } \\
\text { susceptibility minerals such as magnetite }{ }^{5} \text { and } \\
\text { amorphous remnants }^{6}\end{array}$ \\
\hline$\sim 350-600^{\circ} \mathrm{C}$ & illite & Loss of water and lattice collapse ${ }^{7}$ \\
\hline$\sim 400-600^{\circ} \mathrm{C}$ & sedimentary rocks & organic biomarker maturity $^{10,11}$ \\
\hline$\geq 480^{\circ} \mathrm{C}$ & siderite/ankerite & decarbonation $^{8}$ \\
\hline$\sim 500^{\circ} \mathrm{C}$ & montmorillonite & Loss of water and lattice collapse ${ }^{7}$ \\
\hline$\sim 600^{\circ} \mathrm{C}$ & montmorillonite & melting, loss of crystal lattice ${ }^{7}$ \\
\hline$\sim 700-800^{\circ} \mathrm{C}$ & dolomite/dolostone & decarbonation $^{9}$ \\
\hline $\begin{array}{l}\sim 800-850^{\circ} \mathrm{C} \\
\sim 800-900^{\circ} \mathrm{C}\end{array}$ & $\begin{array}{l}\text { illite } \\
\text { calcite/limestone }\end{array}$ & $\begin{array}{l}\text { melting, loss of crystal lattice }{ }^{7} \\
\text { decarbonation }^{9}\end{array}$ \\
\hline
\end{tabular}

support from NSF-EAR Award 1321598. Joe Allen and Marcia Bjørnrud helped improve the clarity, completeness and quality of this manuscript, and we are very grateful to them for such thoughtful reviews.

\section{References}

Abe, S., Mair, K., 2009. Effects of gouge fragment shape on fault friction: New 3d modelling results. Geophysical Research Letters 36 (23).

Allen, A. R., 1979. Mechanism of frictional fusion in fault zones. Journal of Structural Geology 1 (3), 231-243. 
Allen, J. L., 2005. A multi-kilometer pseudotachylyte system as an exhumed record of earthquake rupture geometry at hypocentral depths (Colorado, USA). Tectonophysics $402,37-54$.

Allen, J. L., O'Hara, K. D., Moecher, D. P., 2002. Structural geometry and thermal history of pseudotachylyte from the Homestake shear zone, Sawach Range, Colorado. Geological Society of America Field Guides 3, 17-32.

Allen, J. L., Shaw, C. A., 2011. Seismogenic structure of a crystalline thrust fault: fabric anisotropy and coeval pseudotachylyte-mylonitic pseudotachylyte in the Grizzly Creek Shear Zone, Colorado. In: Geology of the Earthquake Source: A Volume in Honour of Rick Sibson. Vol. 359 of Special Publications. Geological Society, London, pp. 135-151.

Ampuero, J.-P., Ben-Zion, Y., 2008. Cracks, pulses, and macroscopic asymmetry of dynamic rupture on a bilateral interface with velocity-weakening friction. Geophysical Journal International 173, 674-692.

An, L.-J., Sammis, C. G., 1994. Particle size distribution of cataclastic fault materials from Southern California: A 3-D study. Pure and Applied Geophysics $143(1 / 2 / 3), 203-227$.

Anthony, J. L., Marone, C., 2005. Influence of particle characteristics on granular friction. Journal of Geophysical Research 110 (B08409), 14.

Austin, N. J., Kennedy, L. A., Logan, J. M., Rodway, R., 2005. Textural controls on the brittle deformation of dolomite: the transition from brittle faulting to cataclastic flow. In: Gapais, D., Brun, J. P., Cobbold, P. R. (Eds.), Deformation Mechanisms, Rheology and Tectonics: from Minerals to the Lithosphere. Vol. 243 of Special Publications. Geological Society, London, pp. 51-66.

Austrheim, H., Andersen, T. B., 2004. Pseudotachylytes from Corsica: fossil earthquakes from a subduction complex. Terra Nova 16, 193-197.

Auzende, A.-L., Escartin, J., Walte, N. P., Guillot, S., Hirth, G., Frost, D. J., 2015. Deformation mechanisms of antigorite serpentine at subduction zone conditions determined from experimentally and naturally deformed rocks. Earth and Planetary Science Letters 441, 229-240.

Baker, P. A., Kastner, M., 1981. Constraints on the formation of sedimentary dolomite. Science 213, 214-216.

Barker, C. E., Pawlewicz, M. J., 1986. The correlation of vitrinite reflectance with maximum temperature in humic organic matter. In: Buntebarth, G., Lefler, J. (Eds.), Paleogeothermics: Evaluation of Geothermal Conditions in the Geological Past. Vol. 5 of Lecture Notes in Earth Sciences. Springer, Berlin/Heidelberg, pp. 79-93. 
Beeler, N. M., Tullis, T. E., Goldsby, D. L., 2008. Constitutive relationships and physical basis of fault strength due to flash heating. Journal of Geophysical Research: Solid Earth 113 (B1), 12.

URL http://dx.doi.org/10.1029/2007JB004988

Behr, W. M., Platt, J. P., 2011. A naturally constrained stress profile through the middle crust in an extensional terrane. Earth and Planetary Science Letters 303 (3), 181-192.

Ben-Zion, Y., Andrews, D., 1998. Properties and implications of dynamic rupture along a material interface. Bulletin of the Seismological Society of America 88 (4), $1085-1094$.

Beroza, G. C., Mikumo, T., 1996. Short slip duration in dynamic rupture in the presence of heterogeneous fault properties. Journal of Geophysical Research: Solid Earth (1978-2012) 101 (B10), 22449-22460.

Bestmann, M., Pennacchioni, G., Nielsen, S., Göken, M., de Wall, H., 2012. Deformation and ultrafine dynamic recrystallization of quartz in pseudotachylytebearing brittle faults: A matter of a few seconds. Journal of Structural Geology 38 (2), 21-38.

Beutner, E. C., Gerbi, G. P., 2005. Catastrophic emplacement o the Heart Mountain block slide, Wyoming and Montana, USA. Geological Society of America Bulletin $117(5 / 6), 724-735$.

Bhat, H. S., Dmowska, R., King, G. C., Klinger, Y., Rice, J. R., 2007. Off-fault damage patterns due to supershear ruptures with application to the $2001 \mathrm{mw}$ 8.1 kokoxili (kunlun) tibet earthquake. Journal of Geophysical Research: Solid Earth 112 (B6).

Bhat, H. S., Rosakis, A. J., Sammis, C. G., 2012. A micromechanics based constitutive model for brittle failure at high strain rates. Journal of Applied Mechanics 79 (3), 031016.

Bhatty, J. I., 1991. A review of the application of thermal analysis to cementadmixture systems. Thermochimica Acta 189, 313-350.

Billi, A., Di Toro, G., 2008. Fault-related carbonate rocks and earthquake indicators: Recent advances and future trends. In: Landlowe, S. J., Hammler, G. M. (Eds.), Structural Geology: New Research. Nova Science Publishers, Inc., p. 24.

Bistacchi, A., Griffith, W. A., Smith, S. A. F., Di Toro, G., Jones, R., Nielsen, S., 2011. Fault roughness at seismogenic depths from LiDAR and photogrammetric analysis. Pure and Applied Geophysics 68 (12), 2345-2363.

Bjørnerud, M., 2010. Rethinking conditions necessary for pseudotachylyte formation: Observations from the Otago schists, South Island, New Zealand. Tectonophysics 490, 69-80. 
Bjørnerud, M., Magloughlin, J. F., 2004. Pressure-related feedback processes in the generation of pseudotachylytes. Journal of Structural Geology 26, 2317-2323.

Bonfanti, P., Genzano, N., Heinicke, J., Italiano, F., Martinelli, G., Pergola, N., Telesca, L., Tramutoli, V., 2012. Evidence of $\mathrm{CO}_{2}$-gas emission variations in the central Apennines (Italy) during the L'Aquila seismic sequence (March-April 2009). Bollettino di Geofisica Teorica ed Applicata 53 (1), 147-168.

Borradaile, G. J., 1981. Particulate flow of rock and the formation of cleavage. Tectonophysics $72,305-321$.

Bouchon, M., 1997. The state of stress on some faults of the San Andreas system as inferred from near-field strong motion data. Journal of Geophysical Research 102 (B6), 11731-11744.

Boullier, A.-M., Yeh, E.-C., Boutareaud, S., Song, S.-R., Tsai, C.-H., 2009. Microscale anatomy of the 1999 Chi-Chi earthquake fault zone. Geochemistry Geophysics Geosystems 10 (3), doi: 10.1029/2008GC002252.

Boulton, C., Carpenter, B. M., Toy, V., Marone, C., 2012. Physical properties of surface outcrop cataclastic fault rocks, Alpine Fault, New Zealand. Geochemistry Geophysics Geosystems 13 (1).

Boutareaud, S., Boullier, A.-M., Andréani, M., Calugaru, D.-G., Beck, P., Song, S.R., Shimamoto, T., 2010. Clay clast aggregates in gouges: New textural evidence for seismic faulting. Journal of Geophysical Research 115 (B02408), 15.

Boutareaud, S., Calugaru, D.-G., Han, R., Fabbri, O., Mizoguchi, K., Tsutsumi, A., Shimamoto, T., 2008. Clay-clast aggregates: A new textural evidence for seismic fault sliding? Geophysical Research Letters 35, 5 .

Brace, W. F., Kohlstedt, D. L., 1980. Limits on lithospheric stress imposed by laboratory experiments. Journal of Geophysical Research 85 (B11), 6248-6252.

Bradbury, K. K., Evans, J. P., Chester, J. S., Chester, F. M., Kirschner, D. L., 2011. Lithology and internal structure of the San Andreas fault at depth based on characterization of Phase 3 whole-rock core in the San Andreas Fault Observatory at Depth (SAFOD) borehole. Earth and Planetary Science Letters 301, 131-144.

Brantut, N., Han, R., Shimamoto, T., Findling, N., Schubnel, A., 2011. Fast slip with inhibited temperature rise due to mineral dehydration: Evidence from experiments on gypsum. Geology 39 (1), 59-62.

Brantut, N., Schubnel, A., Corvisier, J., Sarout, J., 2010. Thermochemical pressurization of faults during seismic slip. Journal of Geophysical Research 115 (B05314), doi: 10.1029/2009JB006533. 
Brantut, N., Schubnel, A., Rouzaud, J.-N., Brunet, F., Shimamoto, T., 2008. High-velocity frictional properties of a clay-bearing fault gouge and implications for earthquake mechanics. Journal of Geophysical Research 113 (B10401), doi: 10.1029/2007JB005551.

Broberg, K. B., 1999. Cracks and fracture. Academic Press.

Brodsky, E. E., Rowe, C. D., Meneghini, F., Moore, J. C., 2009. A geological fingerprint of extremely low viscosity fault fluids mobilized during an earthquake. Journal of Geophysical Research 114 (B01303), 14, doi: 10.1029/2008JB005633.

Brune, J., 2001. Fault-normal dynamic unloading and loading: An explanation for "non-gouge" rock powder and lack of fault parallel shear bands along the San Andreas Fault. Eos Transactions AGU, Fall Meeting Supplement, Abstract S22B-0655.

Brune, J. N., 1976. The physics of earthquake strong motion. In: Lomnitz, C. (Ed.), Seismic Risk and Engineering Decisions. Elsevier Scientific Publishing, pp. 141-177.

Burnham, A. K., Sweeney, J. J., 1989. A chemical kinetic model of vitrinite maturation and reflectance. Geochimica et Cosmochimica Acta 53 (10), 2649-2657.

Bustin, R., 1983. Heating during thrust faulting in the rocky mountains: friction or fiction? Tectonophysics 95 (3), 309-328.

Caine, J. S., Evans, J. P., Forster, C. B., 1996. Fault zone architecture and permeability structure. Geology 24 (11), 1025-1028.

Campbell, C. S., 1990. Rapid granular flows. Annual Reviews in Fluid Mechanics $22,57-92$.

Cardwell, R., Chinn, D., Moore, G., Turcotte, D., 1978. Frictional heating on a fault zone with finite thickness. Geophysical Journal International 52 (3), 525-530.

Carpenter, B. M., Marone, C., Saffer, D. M., 2011. Weakness of the san andreas fault revealed by samples from the active fault zone. Nature Geoscience 4, 251254.

Carr, A., 2000. Suppression and retardation of vitrinite reflectance, part 1. formation and significance for hydrocarbon generation. Journal of Petroleum Geology $23(3), 313-343$.

Carter, N. L., 1965. Basal quartz deformation lamellae; a criterion for recognition of impactites. American Journal of Science 263 (9), 786-806.

Carter, N. L., Officer, C. B., Drake, C. L., 1990. Dynamic deformation of quartz and feldspar: clues to causes of some natural crises. Tectonophysics 171 (1), 373-391. 
Chang, J. C., Lockner, D. A., Reches, Z., 2012. Rapid acceleration leads to rapid weakening in earthquake-like laboratory experiments. Science 338 (6103), 101105.

Chen, X., Madden, A. S., Bickmore, B. R., Reches, Z., 2013. Dynamic weakening by nanoscale smoothing during high-velocity fault slip. Geology 41 (7), 739-742.

Chester, F. M., Chester, J. S., 1998. Ultracataclasite structure and friction processes of the Punchbowl fault, San Andreas system, California. Tectonophysics 295, 199-221.

Chester, F. M., Evans, J. P., Biegel, R. L., 1993. Internal structure and weakening mechanisms of the San Andreas fault. Journal of Geophysical Research 98 (B1), $771-786$.

Chester, F. M., Logan, J. M., 1986. Implications for mechanical properties of brittle faults from observations of the Punchbowl Fault Zone, California. Pure and Applied Geophysics 124 (1/2), 79-106.

Chester, F. M., Logan, J. M., 1987. Composite planar fabric of gouge from the Punchbowl Fault, California. Journal of Structural Geology 9 (5/6), 621-634.

Chester, F. M., Rowe, C., Ujiie, K., Kirkpatrick, J., Regalla, C., Remitti, F., Moore, J. C., Toy, V., Wolfson-Schwehr, M., Bose, S., Kameda, J., Mori, J. J., Brodsky, E. E., Eguchi, N., Toczko, S., Expedition 343 and 343 T Scientists, 2013. Structure and composition of the plate-boundary slip-zone for the 2011 Tohoku-oki earthquake. Science 342, 1208-1211.

Chester, J. S., Chester, F. M., Kronenberg, A. K., 2005. Fracture surface energy of the Punchbowl fault, San Andreas system. Nature 437, 133-136, doi:10.1038/nature03942.

Cladouhos, T. T., 1999. Shape preferred orientations of survivor grains in fault gouge. Journal of Structural Geology 21, 419-436.

Cloos, E., 1932. feather joints as indicators of the direction of movements on faults, thrusts, joints and magmatic contacts. Proceedings of the National Academy of Sciences of the United States of America 18 (5), 387.

Collettini, C., Carpenter, B. M., Viti, C., Cruciani, F., Mollo, S., Tesei, T., Trippetta, F., Valoroso, L., Chiaraluce, L., 2014. Fault structure and slip localization in carbonate-bearing normal faults: An example from the Northern Apennines of Italy. Journal of Structural Geology 67, 154-166.

Collettini, C., Niemeijer, A., Viti, C., Marone, C., 2009. Fault zone fabric and fault weakness. Nature 462, doi: 10.1038/nature08585.

Collettini, C., Viti, C., Tesei, T., Mollo, S., 2013. Thermal decomposition along natural carbonate faults during earthquakes. Geology 41 (8), 927-930. 
Cowan, D. S., 1999. Do faults preserve a record of seismic slip? A field geologist's opinion. Journal of Structural Geology 21, 995-1001.

Cowan, D. S., Cladouhos, T. T., Morgan, J. K., 2003. Structural geology and kinematic history of rocks formed along low-angle faults, Death Valley, California. Geological Society of America Bulletin 115 (10), 1230-1248.

Craddock, J. P., Geary, J., Malone, D. H., 2012. Vertical injectites of detachment carbonate ultracataclasite at White Mountain, Heart Mountain detachment, Wyoming. Geology 40 (5), 436-466.

Crider, J. G., accepted. The initiation of brittle faults in crystalline rock. Journal of Structural Geology.

Crider, J. G., Cooke, M. L., Willemse, E. J., Arrowsmith, J. R., 1996. Linear-elastic crack models of jointing and faulting. Computer Methods in the Geosciences 15, 359-388.

Currie, C., Hyndman, R. D., Wang, K., Kostoglodov, V., 2002. Thermal models of the Mexico subduction zone: Implications for the megathrust seismogenic zone. Journal of Geophysical Research 107 (B12).

Dalla Torre, M., Ferreiro Mählmann, R., Ernst, W., 1997. Experimental study on the pressure dependence of vitrinite maturation. Geochimica et Cosmochimica Acta 61 (14), 2921-2928.

De Paola, N., Chiodini, G., Hirose, T., Cardellini, C., Caliro, S., Shimamoto, T., 2011a. The geochemical signature caused by earthquake propagation in carbonate-hosted faults. Earth and Planetary Science Letters 310, 225-232.

De Paola, N., Hirose, T., Mitchell, T., Toro, G. D., Viti, C., Shimamoto, T., 2011b. Fault lubrication and earthquake propagation in thermally unstable rocks. Geology 39, 35-38, doi: 10.1130/G31398.1.

Den Hartog, S., Marone, C., Niemeijer, A., Saffer, D., 2014. Friction of megathrust gouges at in-situ subduction zone conditions: strength, rate dependence, and microphysical mechanisms. Eos Transactions AGU, Fall Meeting Supplement, Abstract S11B-4348.

Di Toro, G., Goldsby, D. L., Tullis, T. E., 2004. Friction falls toward zero in quartz rock as slip velocity approaches seismic rates. Nature 427, 436-439.

Di Toro, G., Han, R., Hirose, T., Paola, N. D., Nielsen, S., Mizoguchi, K., Ferri, F., Cocco, M., Shimamoto, T., 2011. Fault lubrication during earthquakes. Nature 471, 494-498, doi: 10.1038/nature09838.

Di Toro, G., Hirose, T., Nielsen, S., Pennacchioni, G., Shimamoto, T., 2006a. Natural and experimental evidence of melt lubrication of faults during earthquakes. Science 311, 647-649. 
Di Toro, G., Hirose, T., Nielsen, S., Shimamoto, T., 2006b. Relating high-velocity rock-friction experiments to coseismic slip in the presence of melts. In: Abercrombie, R., McGarr, A., Kanamori, H., Di Toro, G. (Eds.), Earthquakes: Radiated Energy and the Physics of Faulting: Geophysical Monograph 170. American Geophysical Union, pp. 121-134.

Di Toro, G., Nielsen, S., Pennacchioni, G., 2005. Earthquake rupture dynamics frozen in exhumed ancient faults. Nature 446, 1009-1012.

Di Toro, G., Pennacchioni, G., 2004. Superheated friction-induced melts in zoned pseudotachylytes within the Adamello tonalites (Italian Southern Alps). Journal of Structural Geology 26, 1783-1801.

Di Toro, G., Pennacchioni, G., 2005. Fault plane processes and mesoscopic structure of a strong-type seismogenic fault in tonalites (Adamello batholith, Southern Alps). Tectonophysics 402, 55-80.

Di Toro, G., Pennacchioni, G., Nielsen, S., 2009. Pseudotachylytes and earthquake source mechanics. In: Fukuyama, E. (Ed.), Fault-zone Properties and Earthquake Rupture Dynamics, International Geophysics Series. Vol. 94. Elsevier Academic Press, pp. 87-133, iSBN-13: 978-0-12-374452-4.

Dietz, R. S., 1959. Shatter cones in cryptoexplosion structures (meteorite impact?). The Journal of Geology, 496-505.

Doan, M. L., Billi, A., 2011. High strain rate damage of Carrara marble. Geophysical Research Letters 38.

Doan, M. L., dHour, V., 2012. Effect of initial damage on rock pulverization along faults. Journal of Structural Geology 45, 113-124.

Doan, M. L., Gary, G., 2009. Rock pulverization at high strain rate near the San Andreas fault. Nature Geoscience 2, 709-712.

Dor, O., Ben-Zion, Y., Rockwell, T. K., Brune, J., 2006a. Pulverized rocks in the Mojave section of the San Andreas Fault Zone. Earth and Planetary Science Letters $245,642-654$.

Dor, O., Rockwell, T. K., Ben-Zion, Y., 2006b. Geological observations of damage asymmetry in the structure of the San Jacinto, San Andreas, and Punchbowl Faults in Southern California: a possible indicator for preferred rupture propagation direction. Pure and Applied Geophysics 163, 301-349.

Dunham, E. M., Belanger, D., Cong, L., Kozdon, J. E., 2011. Earthquake ruptures and strongly rate-weakening friction and off-fault plasticity: 2. Nonplanar faults. Bulletin of the Seismological Society of America 101 (5), 2308-2322.

Engelder, J. T., 1974. Cataclasis and the generation of fault gouge. Geological Society of America Bulletin 85 (10), 1515-1522. 
Evans, J. P., 1988. Deformation mechanisms in granitic rocks at shallow crustal levels. Journal of Structural Geology 10 (5), 437-443.

Evans, J. P., Prante, M. R., Janecke, S. U., Ault, A. K., Newell, D. L., 2014. Hot faults: Iridescent slip surfaces with metallic luster document high-temperature ancient seismicity in the Wasatch fault zone, Utah, USA. Geology 42 (7), 623626.

Faber, C., Rowe, C. D., Miller, J. A., Fagereng, r., Neethling, J. H., 2014. Silica gel in fault slip surface: field evidence for palaeoearthquakes? Journal of Structural Geology 69, 108-121.

Fagereng, r., Diener, J. F. A., 2011. San Andreas Fault tremor and retrograde metamorphism. Geophysical Research Letters 38 (L23303), 6.

Fagereng, r., Smith, Z., Rowe, C. D., Makhubu, B., Sylvester, F. Y. G., 2014. Stress, strain, and fault behavior at a thrust ramp: Insights from the Naukluft thrust, Namibia. Journal of Structural Geology 58, 95-107.

Faulkner, D. R., Lewis, A. C., Rutter, E. H., 2003. On the internal structure and mechanics of large strike-slip fault zones: field observations of the Carboneras fault in southeastern Spain. Tectonophysics 367, 235-251.

Faulkner, D. R., Mitchell, T. M., Behnsen, J., Hirose, T., Shimamoto, T., 2011. Stuck in the mud? Earthquake nucleation and propagation through accretionary forearms. Geophysical Research Letters 38 (L18303), doi:10.1029/2011GL048552.

Ferri, F., Di Toro, G., Hirose, T., Shimamoto, T., 2010. Evidence of thermal pressurization in high-velocity friction experiments on smectite-rich gouges. Terra Nova 22 (5), 347-353, doi: 10.1111/j.1365-3121.2010.00955.x.

Fisher, D., Byrne, T., 1987. Structural evolution of underthrusted sediments, Kodiak Islands, Alaska. Tectonics 6 (6), 775-793.

Fondriest, M., Smith, S. A. F., Candela, T., Nielsen, S. B., Mair, K., Di Toro, G., 2013. Mirror-like faults and power dissipation during earthquakes. Geology 41 (11), 1175-1178.

Fondriest, M., Smith, S. A. F., Di Toro, G., Zampieri, D., Mittempergher, S., 2012. Fault zone structure and seismic slip location in dolostones, an example from the Southern Alps, Italy. Journal of Structural Geology 45, 52-67.

French, B. M., 1998. Traces of catastrophe: A handbook of shock-metamorphic effects in terrestrial meteorite impact structures. Technical Report, LPI-Contrib9541.

French, B. M., Cordua, W. S., Plescia, J., 2004. The rock elm meteorite impact structure, wisconsin: Geology and shock-metamorphic effects in quartz. Geological Society of America Bulletin 116 (1-2), 200-218. 
French, M. E., Kitajima, H., Chester, J. S., Chester, F. M., Hirose, T., 2014. Displacement and dynamic weakening processes in smectite-rich gouge from the Central Deforming Zone of the San Andreas Fault. Journal of Geophysical Research Solid Earth 119, 1777-1802.

Freund, L., 1990. The driving force for glide of a threading dislocation in a strained epitaxial layer on a substrate. Journal of the Mechanics and Physics of Solids 38 (5), 657-679.

Freund, L. B., 1998. Dynamic Fracture Mechanics. Cambridge Monographs on Mechanics and Applied Mathematics. Cambridge University Press.

Fulton, P. M., Harris, R. N., 2012. Thermal considerations in inferring frictional heating from vitrinite reflectance and implications for shallow coseismic slip within the nankai subduction zone. Earth and Planetary Science Letters 335, 206-215.

Gash, P. S., 1971. Dynamic mechanism for the formation of shatter cones. Nature $230(10), 32-35$.

Goldsby, D. L., Tullis, T. E., 2002. Low frictional strength of quartz rocks at subseismic slip rates. Geophysical Research Letters 29 (17), 1844-1847.

Goldsby, D. L., Tullis, T. E., 2011. Flash heating leads to low frictional strength of crustal rocks at earthquake slip rates. Science 334 (6053), 216-218. URL http://www . sciencemag . org/content/334/6053/216. abstract

Gomberg, J., Rubinstein, J. L., Peng, Z., Creager, K. C., Vidale, J. E., Bodin, P., 2008. Widespread triggering of nonvolcanic tremor in California. Science 319, 173.

Griffith, A. A., 1921. The phenomena of rupture and flow in solids. Philosophical transactions of the royal society of London. Series A, 163-198.

Griffith, W. A., Di Toro, G., Pennacchioni, G., Pollard, D. D., 2008. Thin pseudotachylytes in faults of the Mt. Abbot quadrangle, Sierra Nevada: physical constraints for small seismic slip events. Journal of structural geology 30 (9), 1086-1094.

Griffith, W. A., Mitchell, T. M., Renner, J., Di Toro, G., 2012. Coseismic damage and softening of fault rocks at seismogenic depths. Earth and Planetary Science Letters 353-354, 219-230.

Griffith, W. A., Nielsen, S., Di Toro, G., Smith, S. A. F., 2010. Rough faults, distributed weakening, and off fault deformation. Journal of Geophysical Research 115 (B08409), doi: 10.1029/2009JB006925. 
Griffith, W. A., Rosakis, A., Pollard, D. D., Ko, C. W., 2009. Dynamic rupture experiments elucidate tensile crack development during propagating earthquake ruptures. Geology 37, 795-798, doi: 10.1130/G30064A.1.

Grim, R. E., Bradley, W. F., 1940. Investigation of the effect of heat on the clay minerals illite and montmorillonite. Journal of the American Ceramic Society 23 (8), 242-248.

Hadizadeh, J., Tullis, T. E., White, J. C., 2015. Shear localization, velocity weakening behavior, and development of cataclastic foliation in experimental granite gouge. Journal of Structural Geology in press.

Hamada, Y., Hirono, T., Ishikawa, T., 2011. Coseismic frictional heating and fluidrock interaction in a slip zone within a shallow accretionary prixm and implications for earthquake slip behavior. Journal of Geophysical Research 116 (B01302), doi:110.1029/2010JB007730.

Hamers, M. F., Drury, M. R., 2011. Scanning electron microscopecathodoluminescence (SEM-CL) imaging of planar deformation features and tectonic deformation lamellae in quartz. Meteoritics \& Planetary Science 46 (12), $1814-1831$.

Han, R., Hirose, T., 2012. Clay-clast aggregates in fault gouge: An unequivocal indicator of seismic faulting at shallow depths? Journal of Structural Geology $43,92-99$.

Han, R., Hirose, T., Shimamoto, T., 2010. Strong velocity weakening and powder lubrication of simulated carbonate faults at seismic slip rates. Journal of Geophysical Research 115 (B03412), doi: 10.1029/2008JB006136.

Han, R., Hirose, T., Shimamoto, T., Lee, Y., ichi Ando, J., 2011. Granular nanoparticles lubricate faults during seismic slip. Geology 39 (6), 599-602, doi:10.1130/G31842.1.

Han, R., Shimamoto, T., Ando, J.-i., Ree, J.-H., 2007a. Seismic slip record in carbonate-bearing fault zones: An insight from high-velocity friction experiments on siderite gouge. Geology 35, 1131-1134, doi: 10.1030/G24106A.1.

Han, R., Shimamoto, T., Hirose, T., Ree, J.-H., Ando, J.-i., 2007b. Ultralow friction of carbonate faults caused by thermal decomposition. Science 316, doi: 10.1126/science.1139763.

Harris, R. A., Barall, M., Andrews, D., Duan, B., Ma, S., Dunham, E., Gabriel, A.A., Kaneko, Y., Kase, Y., Aagaard, B., et al., 2011. Verifying a computational method for predicting extreme ground motion. Seismological Research Letters $82(5), 638-644$. 
Heaton, T. H., 1990. Evidence for and implications of self-healing pulses of slip in earthquake rupture. Physics of the Earth and Planetary Interiors 64 (1), 1-20.

Heesakkers, V., Murphy, S., Reches, Z., 2011. Earthquake rupture at focal depth, Part 1: Structure and rupture of the Pretorius Fault, TauTona Mine, South Africa. Pure and Applied Geophysics 168, 2395-2425.

Heilbronner, R., Keulen, N., 2006. Grain size and shape analysis of fault rocks. Tectonophysics 427, 199-216.

Hirono, T., Lin, W., Yeh, E.-C., Soh, W., Hashimoto, Y., Sone, H., Matsubayashi, O., Aoike, K., Ito, H., Kinoshita, M., Murayama, M., Song, S.-R., Ma, K.-F., Hung, J.-H., Wang, C.-Y., , Tsai, Y.-B., 2006. High magnetic susceptibility of fault gouge within Taiwan Chelungpu fault: Nondestructive continuous measurements of physical and chemical properties in fault rocks recovered from Hole B, TCDP. Geophysical Research Letters 33 (L15303).

Hirono, T., Ujiie, K., Ishikawa, T., Mishima, T., Hamada, Y., Tanimizu, M., Soh, W., Kinoshita, M., 2009. Estimation of temperature rise in a shallow slip zone of the megasplay fault in the nankai trough. Tectonophysics 478 (3), 215-220.

Hirose, T., Bystricky, M., 2007. Extreme dynamic weakening of faults during dehydration by coseismic shear heating. Geophysical Research Letters 34 (L14311).

Hirose, T., Mizoguchi, K., Shimamoto, T., 2012. Wear processes in rocks at slow to high slip rates. Journal of Structural Geology 38, 102-116.

Hirth, G., Teyssier, C., Dunlap, W. J., 2001. An evaluation of quartzite flow laws based on comparisons between experimentally and naturally deformed rocks. International Journal of Earth Sciences 90, 77-87.

Honda, G., Ishikawa, T., Hirono, T., Mukoyoshi, H., 2011. Geochemical signals for determining slip-weakening mechanism of an ancient megasplay fault in the Shimanto accretionary complex. Geophysical Research Letters 38 (L06310), doi:10.1029/2011GL046722.

Hyndman, R. D., Yamano, M., Oleskevich, D. A., 1997. The seismogenic zone of subduction thrust faults. The Island Arc 6, 224-260.

Ide, S., Beroza, G. C., Shelly, D. R., Takahiko, U., 2007. A scaling law for slow earthquakes. Nature 447.

Ikari, M. J., Kameda, J., Saffer, D. M., Kopf, A. J., 2015. Strength characteristics of japan trench borehole samples in the high-slip region of the 2011 tohoku-oki earthquake. Earth and Planetary Science Letters 412, 35-41.

Ikari, M. J., Saffer, D. M., Marone, C., 2007. Effect of hydration state on the frictional properties of montmorillonite-based fault gouge. Journal of Geophysical Research 112 (B06423). 
Ikari, M. J., Saffer, D. M., Marone, C., 2009. Frictional and hydrologic properties of clay-rich fault gouge. Journal of Geophysical Research: Solid Earth (1978-2012) 114 (B5).

Inglis, C. E., 1913. Stresses in a plate due to the presence of cracks and sharp corners. Royal Institute of Naval Architects Transactions 55, 219-230.

Isambert, A., Valet, J.-P., Gloter, A., Guyot, F., 2003. Stable mn-magnetite derived from mn-siderite by heating in air. Journal of Geophysical Research 108, 2283, doi:10.1029/2002JB002099.

Ishikawa, T., Tanimizu, M., Nagaishi, K., Matsuoka, J., Tadai, O., Sakaguchi, M., Hirono, T., Mishima, T., Tanikawa, W., Lin, W., Kikuta, H., Soh, W., Song, S.R., 2008. Coseismic fluid-rock interactions at high temperatures in the chelungpu fault. Nature Geoscience 1, 679-683.

Ismat, Z., 2013. Block-supported cataclastic flow within the upper crust. Journal of Structural Geology 56, 118-128.

Istok, J. D., Harward, M. E., 1982. Influence of soil moisture on smectite formation in soils derived from serpentinite. Soil Science Society of America Journal 46, $1106-1108$.

Ito, Y., Obara, K., 2006. Very low frequency earthquakes within accretionary prisms are very low stress-drop earthquakes. Geophysical Research Letters 22 (L09302).

Janssen, C., Wirth, R., Lin, A., Dresen, G., 2013. TEM microstructural analysis in a fault gouge sample of the Nojima Fault Zone, Japan. Tectonophysics 583, $101-104$.

Janssen, C., Wirth, R., Rybacki, E., Naumann, R., Kemnitz, H., Wenk, H., Dresen, G., 2010. Amorphous material in SAFOD core samples (San Andreas Fault): Evidence for crush-origin pseudotachylytes? Geophysical Research Letters 37 (1), L01303.

John, T., Medvedev, S., Rüpke, L. H., Andersen, T. B., Podladchikov, Y. Y., Austrheim, H., 2009. Generation of intermediate-depth earthquakes by selflocalizating thermal runaway. Nature Geoscience 2, 137-140.

Kameda, J., Ujiie, K., Yamaguchi, A., Kimura, G., 2011. Smectite to chlorite conversion by frictional heating along a subduction thrust. Earth and Planetary Science Letters 305, 161-170.

Kennedy, L. A., Russell, J. K., 2012. Cataclastic production of volcanic ash at mount saint helens. Physics and Chemistry of the Earth, Parts A/B/C 45, 4049 . 
Keulen, N., Heilbronner, R., Stünitz, H., Boullier, A.-M., Ito, H., 2007. Grain size distributions of fault rocks: A comparison between experimentally and naturally deformed granitoids. Journal of Structural Geology 29, 1282-1300.

Kim, J.-W., Ree, J.-H., Han, R., Shimamoto, T., 2010. Experimental evidence for the simultaneous formation of pseudotachylyte and mylonite in the brittle regime. Geology 38 (12), 1143-1146.

Kirby, S. H., 1983. Rheology of the lithosphere. Reviews of Geophysics and Space Physics 21 (6), 1458-1487.

Kirkpatrick, J. D., Dobson, K. J., Mark, D. F., Shipton, Z. K., Brodsky, E. E., Stuart, F. M., 2012. The depth of pseudotachylyte formation from detailed thermochronology and constraints on coseismic stress drop variability. Journal of Geophysical Research 117 (B06406), doi: 10.1029/2011JB008846.

Kirkpatrick, J. D., Rowe, C. D., 2013. Disappearing ink: How pseudotachylytes are lost from the rock record. Journal of Structural Geology 52, 183-198.

Kirkpatrick, J. D., Rowe, C. D., White, J. C., Brodsky, E. E., 2013. Silica gel formation during fault slip: Evidence from the rock record. Geology 41 (9), $1015-1018$.

Kirkpatrick, J. D., Shipton, Z. K., 2009. Geologic evidence for multiple slip weakening mechanisms during seismic slip in crystalline rock. Journal of Geophysical Research 114 (B12401), doi: 10.1029/2008JB006037.

Kirkpatrick, J. D., Shipton, Z. K., Evans, J. P., Micklethwaite, S., Lim, S. J., McKillop, P., 2008. Strike-slip fault terminations at seismogenic depths; the structure and kinematics of the Glacier Lakes fault, Sierra Nevada, USA. Journal of Geophysical Research 113 (B4), doi: 10.1029/2007JB005311.

Kirkpatrick, J. D., Shipton, Z. K., Persano, C., 2009. Pseudotachylytes: rarely generated, rarely preserved or rarely reported? Bulletin of the Seismological Society of America 99, 382-388, doi: 10.1785/0120080114.

Kondo, H., Kimura, G., Masago, H., Ohmori-Ikehara, K., Kitamura, Y., Ikesawa, E., Sakaguchi, A., Yamaguchi, A., Okamoto, S., 2005. Deformation and fluid flow of a major out-of sequence thrust located at seismogenic depth in an accretionary complex: Nobeoka Thrust in the Shimanto Belt, Kyushu, Japan. Tectonics 24 (TC6008).

Kuo, L.-W., Li, H., Smith, S. A., Di Toro, G., Suppe, J., Song, S.-R., Nielsen, S., Sheu, H.-S., Si, J., 2014. Gouge graphitization and dynamic fault weakening during the $2008 \mathrm{Mw} 7.9$ Wenchuan earthquake. Geology 42 (1), 47-50.

Kuo, L.-W., Song, S.-R., Huang, L., Yeh, E.-C., Chen, H.-F., 2011. Temperature estimates of coseismic heating in clay-rich fault gouges, the chelungpu fault zones, taiwan. Tectonophysics 502 (3), 315-327. 
Kuo, L.-W., Song, S.-R., Yeh, E.-C., Chen, H.-F., 2009. Clay mineral anomalies in the fault zone of the Chelungpu Fault, Taiwan, and their implications. Geophysical Research Letters 36 (L18306), doi: 10.1029/2009GL039269.

Lamothe, K., Andrews, M., Rowe, C. D., Rempe, M., Mitchell, T., Di Toro, G., 2014. Characterization of wear material associated with silica lubrication. In: GAC-MAC Joint Annual Meeting Abstracts. Vol. 37. Geological Association of Canada, p. 151.

Lay, T., Wallace, T. C., 1995. Modern global seismology. Vol. 58. Academic press.

Lin, A., 1994. Glassy pseudotachylyte veins from the Fuyun fault zone, northwest China. Journal of Structural Geology 16 (1), 71-83.

Lin, A., 1996. Injection veins of crushing-originated pseudotachylyte and fault gouge formed during seismic faulting. Engineering Geology 43, 213-224.

Lin, A., 2008. Fossil Earthquakes: The Formation and Preservation of Pseudotachylytes. Vol. 111 of Lecture Notes in Earth Sciences. Springer.

Lin, A., 2011. Seismic slip recorded by fluidized ultracataclastic veins formed in a coseismic shear zone during the $2008 \mathrm{M}_{W}$ 7.9 Wenchuan earthquake. Geology 39, 547-550, doi: 10.1130/G32065.1.

Lin, A., Maruyama, T., Aaron, S., Michibayashi, K., Camacho, A., Kano, K.-i., 2005. Propagation of seismic slip from brittle to ductile crust: Evidence from pseudotachylyte of the Woodroffe thrust, central Australia. Tectonophysics 402, $21-35$.

Lin, A., Shimamoto, T., 1998. Selective melting processes as inferred from experimentally generated pseudotachylytes. Journal of Asian Earth Sciences 16 (5-6), $533-545$.

Lin, A., Sun, Z., Yang, Z., 2003. Multiple generations of pseudotachylyte in the brittle to ductile regimes, Quinling-Dabie Shan ultrahigh-pressure metamorphic complex, central China. The Island Arc 12, 423-435.

Lindsay, N. G., Murphy, F. C., Walsh, J. J., Watterson, J., 1993. Outcrop studies of shale smears on fault surfaces. In: Bryant, I. D., Flint, S. S. (Eds.), The Geological Modelling of Hydrocarbon Reservoirs and Outcrop Analogues. Special Publication of the International Association of Sedimentology. Vol. 15. John Wiley \& Sons, pp. 113-123.

Lockner, D. A., Morrow, C., Moore, D., Hickman, S., 2011. Low strength of deep San Andreas fault gouge from SAFOD core. Nature 472, doi:10.1038/nature09927. 
Logan, J., Dengo, C., Higgs, N., Wang, Z., 1992. Fabrics of experimental fault zones: Their development and relationship to mechanical behavior. International Geophysics 51, 33-67.

Logan, J. M., Higgs, N., Friedman, M., 1981. Laboratory studies on natural gouge from the us geological survey dry lake valley no. 1 well, san andreas fault zone. Mechanical behavior of crustal rocks: the Handin volume, 121-134.

Loope, D. B., Elder, J. F., Zlotnik, V. A., Kettler, R. M., Pederson, D. T., 2013. Jurassic earthquake sequence recorded by multiple generations of sand blows, Zion National Park, Utah. Geology.

Loveless, J. P., Allmendinger, R. W., Pritchard, M. E., Garroway, J. L., Gonzlez, G., 2011. Surface cracks record long-term seismic segmentation of the Andean margin. Geology 31, 23-26.

Maddock, R. H., 1992. Effects of lithology, cataclasis and melting on the composition of fault-generated pseudotachylytes in Lewisian gneiss, Scotland. Tectonophysics 204, 261-278.

Magloughlin, J. F., 1992. Microstructural and chemical changes associated with cataclasis and frictional melting at shallow crustal levels: the cataclasitepseudotachylyte connection. Tectonophysics 204, 243-260.

Mair, K., Abe, S., 2011. Breaking up: Comminution mechanisms in sheared simulated fault gouge. Pure and Applied Geophysics 168, 2277-2288.

Marone, C., 1998. Laboratory-derived friction laws and their application to seismic faulting. Annual Review of Earth and Planetary Science 26, 643-696.

Mase, C. W., Smith, L., 1987. Effects of frictional heating on the thermal, hydrologic, and mechanical response of a fault. Journal of Geophysical Research 92 (7), 6249-6272.

McIntosh, R. M., Sharp, J. H., Wilburn, F. W., 1990. The thermal decomposition of dolomite. Thermochimica Acta 165 (2), 281-296.

Melosh, B. L., Rowe, C. D., Smit, L., Groenewald, C., Lambert, C. W., Macey, P., 2014. Snap, Crackle, Pop: Dilational fault breccias record seismic slip below the brittle-ductile transition. Earth and Planetary Science Letters 403, 432-445.

Melosh, H. J., 1979. Acoustic fluidization: a new geologic process? Journal of Geophysical Research: Solid Earth (1978-2012) 84 (B13), 7513-7520.

Meneghini, F., Di Toro, G., Rowe, C. D., Moore, J. C., Tsutsumi, A., Yamaguchi, A., 2010. Record of mega-earthquakes in subduction thrusts: the black fault rocks of Pasagshak Point (Kodiak Island, Alaska). Geological Society of America Bulletin 122 (7/8), 1280-1297, doi: 10.1030/B30049.1. 
Meng, L., Inbal, A., Ampuero, J.-P., 2011. A window into the complexity of the dynamic rupture of the $2011 \mathrm{Mw} 9$ Tohoku-Oki earthquake. Geophysical Research Letters 38 (L00G07), 7.

Mishima, T., Hirono, T., Soh, W., Song, S.-R., 2006. Thermal history estimation of the Taiwan Chelungpu fault using rock-magnetic methods. Geophysical Research Letters 33 (L23311), doi: 10.1029/2006GL028088.

Mitchell, T. M., Ben-Zion, Y., Shimamoto, T. ., 2011. Pulverized fault rocks and damage asymmetry along the Arima-Takatsuki Tectonic Line, Japan. . Earth and Planetary Science Letters 308, 284-297.

Mitchell, T. M., Billi, A., Miller, S. A., Goldsby, D. L., Scholz, C. H., Gran, J. K., Simons, J., 2013. Dynamic pulverization by rapid decompression. Eos Transactions AGU, Fall Meeting Supplement, Abstract MR41B-04.

Mitchell, T. M., Faulkner, D. R., 2009. The nature and origin of off-fault damage surrounding strike-slip fault zones with a wide range of displacements: A field study from the Atacama fault system, northern Chile. Journal of Structural Geology 31, 802-816, doi: 10.1016/j.jsg.2009.05.002.

Mitchell, T. M., Smith, S. A., Anders, M. H., Di Toro, G., Nielsen, S., Cavallo, A., Beard, A. D., 2015. Catastrophic emplacement of giant landslides aided by thermal decomposition: Heart mountain, wyoming. Earth and Planetary Science Letters 411, 199-207.

Mittempergher, S., Dallai, L., Pennacchioni, G., Renard, F., Di Toro, G., 2014. Origin of hydrous fluids at seismogenic depth: Constraints from natural and experimental fault rocks. Earth and Planetary Science Letters 385, 97-109.

Mittempergher, S., Pennacchioni, G., Toro, G. D., 2009. The effects of fault orientation and fluid infiltration on fault rock assemblages at seismogenic depths. Journal of Structural Geology 31, 1511-1524.

Mizoguchi, K., Hirose, T., Shimamoto, T., Fukuyama, E., 2007. Reconstruction of seismic faulting by high-velocity friction experiments: An example of the 1995 kobe earthquake. Geophysical Research Letters 34 (1).

Mizoguchi, K., Hirose, T., Shimamoto, T., Fukuyama, E., 2009. High-velocity frictional behavior and microstructure evolution of fault gouge obtained from the Nojima fault, southwest Japan. Tectonophysics 471, 285-296.

Moecher, D. P., Steltenpohl, M. G., 2009. Direct calculation of rupture depth for an exhumed paleoseismogenic fault from mylonitic pseudotachylyte. Geology 37 (11), 999-1002.

Monzawa, N., Otsuki, K., 2003. Comminution and fluidization of granular fault materials: implications for fault slip behavior. Tectonophysics 367, 127-143. 
Moore, J. C., Rowe, C., Meneghini, F., 2007. How can accretionary prisms elucidate seismogenesis in subduction zones? In: Dixon, T., Moore, J. C. (Eds.), Seismogenic Zone of Subduction Thust Faults. Vol. 2 of MARGINS Theoretical and Experimental Earth Science Series. Columbia University Press, p. 692.

Moore, J. C., Saffer, D., 2001. Updip limit of the seismogenic zone beneath the accretionary prism of southwest Japan: An effect of diagenetic to low-grade metamorphic processes and increasing effective stress. Geology 29 (22), 183-186.

Morrow, C., Shi, L., Byerlee, J., 1982. Strain hardening and strength of clay-rich fault gouges. Journal of Geophysical Research: Solid Earth (1978-2012) 87 (B8), 6771-6780.

Mutlu, O., Pollard, D. D., 2008. On the patterns of wing cracks along an outcrop scale flaw: A numerical modeling approach using complementarity. Journal of Geophysical Research 113 (4B).

Nakamura, Y., Oohashi, K., Toyoshima, T., Satish-Kumar, M., Akai, J., 2015. Strain-induced amorphization of graphite in fault zones of the Hidaka metamorphic belt, Hokkaido, Japan. Journal of Structural Geology 72, 142-161.

Nestola, F., Mittempergher, S., Di Toro, G., Zorzi, F., Pedron, D., 2010. Evidence of dmisteinbergite (hexagonal form of $\mathrm{CaAl}_{2} \mathrm{Si}_{2} \mathrm{O}_{8}$ ) in pseudotachylyte: A tool to constrain the thermal history of a seismic event. American Mineralogist 95, 405-409.

Ngo, D., Huang, Y., Rosakis, A., Griffith, W. A., Pollard, D., 2012. Off-fault tensile cracks: A link between geological fault observations, lab experiments, and dynamic rupture models. Journal of Geophysical Research 117.

Nielsen, S., Di Toro, G., Hirose, T., Shimamoto, T., 2008. Frictional melt and seismic slip. Journal of Geophysical Research 113 (B01308), doi: 10.1029/2007JB005122.

Nielsen, S., Toro, G., Griffith, W., 2010. Friction and roughness of a melting rock surface. Geophysical Journal International 182 (1), 299-310.

Niemeijer, A., Di Toro, G., Griffith, W. A., Bistacchi, A., Smith, S. A. F., Nielsen, S., 2012. Inferring earthquake physics and chemistry using an integrated field and laboratory approach. Journal of Structural Geology 39, 2-36.

Niemeijer, A. R., Spiers, C. J., 2005. Influence of phyllosilicates on fault strength in the brittle-ductile transition: insights from rock analog experiments. In: Bruhn, D., Burlini, L. (Eds.), High-Strain Zones: Structure and Physical Properties. Vol. 245 of Special Publications. Geological Society of London, pp. 303-327.

Niemeijer, A. R., Spiers, C. J., 2006. Velocity dependence of strength and healing behaviour in simulated phyllosilicate-bearing fault gouge. Tectonophysics 427, 231-253. 
Niemeijer, A. R., Vissers, R. L. M., 2014. Earthquake rupture propagation inferred from the spatial distribution of fault rock frictional properties. Earth and Planetary Science Letters 396, 154-164.

Noda, H., Lapusta, N., 2013. Stable creeping fault segments can become destructive as a result of dynamic weakening. Nature 493 (7433), 518-521.

Numelin, T., Marone, C., Kirby, E., 2007. Frictional properties of natural fault gouge from a low-angle normal fault, Panamint Valley, California. Tectonics 26 (TC2004).

Obara, K., Hirose, H., Yamamizu, F., Kasahara, K., 2004. Episodic slow slip events accompanied by non-volcanic tremors in southwest japan subduction zone. Geophysical Research Letters 31 (L23602), 4.

O'Hara, K., 2004. Paleo-stress estimates on ancient seismogenic faults based on frictional heating of coal. Geophysical Research Letters 31 (3), 4.

O'Hara, K., Mizoguchi, K., Shimamoto, T., Hower, J. C., 2006. Experimental frictional heating of coal gouge at seismic slip rates: Evidence for devolatilization and thermal pressurization of gouge fluids. Tectonophysics 424, 109-118.

Ohnaka, M., 2003. A constitutive scaling law and a unified comprehension for frictional slip failure, shear fracture of intact rock, and earthquake rupture. Journal of Geophysical Research: Solid Earth (1978-2012) 108 (B2).

Okura, Y., Kitahara, H., Ochiai, H., Sammori, T., Kawanami, A., 2002. Landslide fluidization process by flume experiments. Engineering Geology 66, 65-78.

Olgaard, Brace, 1983. The microstructure of gouge from a mining-induced seismic shear zone. International Journal of Rock Mechanics Mining Science and Geomechanics Abstracts 20 (1), 11-19.

Oohashi, K., Hirose, T., Shimamoto, T., 2011. Shear-induced graphitization of carbonaceous materials during seismic fault motion: Experiments and possible implications for fault mechanics. Journal of Structural Geology 33, 1122-1134.

Otsuki, K., Monzawa, N., Nagase, T., 2003. Fluidization and melting of fault gouge during seismic slip: Identification in the Nojima fault zone and implications for focal earthquake mechanisms. Journal of Geophysical Research 108 (B42192), 18, doi: 10/1029/2001JB001711, 2003.

Otsuki, K., Uduki, T., Monzawa, N., Tanaka, H., 2005. Clayey injection veins and pseudotachylyte from two boreholes penetrating the Chelungpu Fault, Taiwan: Their implications for the contrastive seismic slip behaviors during the 1999 ChiChi earthquake. The Island Arc 14, 22-36.

Owen, G., Moretti, M., 2011. Identifying triggers for liquefaction-induced softsediment deformation in sands. Sedimentary Geology 235, 141-147. 
Owen, G., Moretti, M., Alfaro, P., 2011. Recognising triggers for soft-sediment deformation: Current understanding and future directions. Sedimentary Geology 235, 133-140.

Ozawa, K., Takizawa, S., 2007. Amorphous material formed by the mechanochemical effect in natural pseudotachylyte of crushing origin: A case study of the Iida-Matsukawa Fault, Nagano Prefecture, Central Japan. Journal of Structural Geology 29, 1855-1869.

Passchier, C. W., 1982. Pseudotachylyte and the development of ultramylonite bands in the Saint-Barthélemy Massif, French Pyrenees. Journal of Structural Geology 4 (1), 69-79.

Passelègue, F. X., Schubnel, A., Nielsen, S., Bhat, H. S., Madariaga, R., 2013. From sub-rayleigh to supershear ruptures during stick-slip experiments on crustal rocks. Science 340 (6137), 1208-1211.

Peacock, S. M., 1996. Thermal and petrologic structure of subduction zones. In: Subduction: Top to Bottom: Geophysical Monograph. Vol. 96. American Geophysical Union, pp. 119-133.

Peacock, S. M., Wang, K., 1999. Seismic consequences of warm versus cool subduction metamorphism: Examples from southwest and northeast Japan. Science 286, 937-939.

Pec, M., Stünitz, H., Heilbronner, R., 2012a. Semi-brittle deformation of granitoid gouges in shear experiments at elevated pressures and temperatures. Journal of Structural Geology 38, 200-221.

Pec, M., Stünitz, H., Heilbronner, R., Drury, M., de Capitani, C., 2012b. Origin of pseudotachylites in slow creep experiments. Earth and Planetary Science Letters 355, 299-310.

Peng, Z., Gomberg, J., 2010. An integrated perspective of the continuum between earthquakes and slow-slip phenomena. Nature Geoscience 3 (9), 599-607.

Pennacchioni, G., 2005. Control of the geometry of precursor brittle structures on the type of ductile shear zone in the Adamello tonalites, Southern Alps (Italy). Journal of Structural Geology 27 (4), 627-644.

Petit, J., 1987. Criteria for the sense of movement on fault surfaces in brittle rocks. Journal of Structural Geology 9 (5), 597-608.

Philpotts, A. R., 1964. Origin of pseudotachylytes. American Journal of Science 262, 1008-1035.

Pittarello, L., Di Toro, G., Bizzarri, A., Pennacchioni, G., Hadizadeh, J., Cocco, M., 2008. Energy partitioning during seismic slip in pseudotachylyte-bearing faults 
(Gole Larghe Fault, Adamello, Italy). Earth and Planetary Science Letters 269, 131-139.

Platt, J. D., Rudnicki, J. W., Rice, J. R., 2014. Stability and localization of rapid shear in fluid-saturated fault gouge: 2. localized zone width and strength evolution. Journal of Geophysical Research: Solid Earth 119 (5), 4334-4359.

Poelchau, M., Kenkmann, T., 2011. Feather features: A low-shock-pressure indicator in quartz. Journal of Geophysical Research: Solid Earth 116 (B2).

Poliakov, A., Dmowska, R., Rice, J., 2002. Dynamic Shear rupture interactions with fault bends and off-axis secondary faulting. Journal of Geophysical Research 107 (B11).

Polissar, P. J., Savage, H. M., Brodsky, E. E., 2011. Extractable organic material in fault zones as a tool to investigate frictional stress. Earth and Planetary Science Letters 311 (3), 439-447.

Pollard, D., Segall, P., 1987. Theoretical displacements and stresses near fractures in rock: with applications to faults, joints, veins, dikes, and solution surfaces. Fracture mechanics of rock 277 (349), 277-349.

Power, W. L., Tullis, T. E., 1989. The relationship between slickenside surfaces in fine-grained quartz and the seismic cycle. Journal of Structural Geology 11 (7), 879-893.

Power, W. L., Tullis, T. E., 1991. Euclidean and fractal models for the description of rock surface roughness. Journal of Geophysical Research: Solid Earth (19782012) 96 (B1), 415-424.

Price, N. A., Johnson, S. E., Gerbi, C. C., David P. West, J., 2012. Identifying deformed pseudotachylyte and its influence on the strength and evolution of a crustal shear zone at the base of the seismogenic zone. Tectonophysics 518-521, $63-83$.

Proctor, B., Mitchell, T., Hirth, G., Goldsby, D., Zorzi, F., Platt, J., Di Toro, G., 2014. Dynamic weakening of serpentinite gouges and bare surfaces at seismic slip rates. Journal of Geophysical Research 119.

Quigley, M. C., Bastin, S., Bradley, B. A., 2013. Recurrent liquefaction in Christchurch, New Zealand, during the Canterbury earthquake sequence. Geology 41 (4), 419-422.

Rabinowitz, H. S., Savage, H. M., Polissar, P., Plank, T., Rowe, C. D., Kirkpatrick, J. D., 2014. Detecting seismic signatures in the rock record at the Japan Trench. Eos Transactions AGU, Fall Meeting Supplement, Abstract S53B-4501. 
Rabinowitz, H. S., Savage, H. M., Polissar, P. J., Plank, T. A., Rowe, C. D., Kirkpatrick, J. D., 2013. Detecting the frictional temperature rise during the 2011 Tohoku Earthquake using the thermal maturity of biomarkers. Eos Transactions AGU, Fall Meeting Supplement, Abstract T41F-07.

Rawling, G. C., Goodwin, L. B., 2003. Cataclasis and particulate flow in faulted, poorly lithified sediments. Journal of Structural Geology 25, 317-313.

Reches, Z., Dewers, T. A., 2005. Gouge formation by dynamic pulverization. Earth and Planetary Science Letters 235, 361-374.

Reimold, W., Andreoli, M., Hart, R., 1988. Microdeformation in vredefort rocks; evidence for shock metamorphism. LPI Contributions 673, 152-153.

Rempe, M., Mitchell, T., J., R., Nippress, S., Ben-Zion, Y., Rockwell, T. ., 2013. Damage and seismic velocity structure of pulverized rocks near the San Andreas Fault. Journal of Geophysical Research 118, doi:10.1002/jgrb.50184.

Rempe, M., Smith, S. A. F., Ferri, F., Mitchell, T. M., Di Toro, G., 2014. Clastcortex aggregates in experimental and natural calcite-bearing fault zones. Journal of Structural Geology 68 (A), 142-157.

Rempel, A. W., Rice, J. R., 2006. Thermal pressurization and onset of melting in fault zones. Journal of Geophysical Research 111 (B09314), doi: 10.10292006JB004314.

Resor, P., Shervais, K., Di Toro, G., Griffith, W. A., 2014. Microroughness variation with inferred changes in fault-normal stress along a pseudotachylyte-bearing fault. Eos Transactions AGU, Fall Meeting Supplement, Abstract T11B-4564.

Rice, J., Sammis, C. G., Parsons, R., 2005. Off-fault secondary failure induced by a dynamic slip-pulse. Bulletin of the Seismological Society of America 95 (1), $109-134$.

Rice, J. R., 2006. Heating and weakening of faults during earthquake slip. Journal of Geophysical Research 111 (B5), B05311.

Rispoli, R., 1981. Stress fields about strike-slip faults inferred from sylolites and tension gashes. Tectonophysics 75, 29-36.

Rodrigues, N., Cobbold, P. R., seth, H. L., 2009. Physical modeling of sand injectites. Tectonophysics 474, 601-632.

Rogers, G., Dragert, H., 2003. Episodic tremor and slip on the Cascadia Subduction Zone: The chatter of silent slip. Science 300, 1942-1943.

Ross, J. A., Peakall, J., Keevil, G. M., 2014. Facies and flow regimes of sandstonehosted columnar intrusions: Insights from the pipes of Kodachrome Basin State Park. Sedimentology 61 (6), 1764-1792. 
Ross, J. V., Bustin, R. M., Rouzaud, J. N., 1991. Graphitization of high rank coals - the role of shear strain: experimental considerations. Organic Geochemistry 17 (5), 585-596.

Rowe, C. D., 2013. Shaking loose: Sand volcanoes and Jurassic earthquakes. Geology 41 (10), 1135-1136.

Rowe, C. D., Backeberg, N. R., 2011. Discussion on: Reconstruction of the Ordovician Pakhuis ice sheet, South Africa, by H. J. Blignault and J. N. Theron. South African Journal of Geology 114 (1), 95-102, doi: 10.2110/gssajg.114.1.95.

Rowe, C. D., Fagereng, r., Miller, J. A., Mapani, B., 2012a. Signature of coseismic decarbonation in dolomite fault rocks of the Naukluft Thrust, Namibia. Earth \& Planetary Science Letters 333-334, 200-210.

Rowe, C. D., Kirkpatrick, J. D., Brodsky, E. E., 2012b. Fault rock injections record paleo-earthquakes. Earth \& Planetary Science Letters 335-336, 154-166.

Rowe, C. D., Meneghini, F., Moore, J. C., 2011. Textural record of the seismic cycle: Strain rate variation in an ancient subduction thrust. In: Geology of the Earthquake Source: A Volume in Honour of Richard Sibson. Vol. 359. Journal of the Geological Society Special Publication, pp. 77-95.

Rowe, C. D., Moore, J. C., Meneghini, F., McKiernan, A. W., 2005. Large-scale pseudotachylytes and fluidized cataclasites from an ancient subduction thrust fault. Geology 33 (12), 937-940.

Rutter, E. H., 1986. On the nomenclature of mode of failure transitions in rocks. Tectonophysics $122,381-387$.

Rutter, E. H., Maddock, R. H., Hall, S. H., White, S. H., 1986. Comaparative microstructures of naturally and experimentally produced clay-bearing fault gouges. Pure and Applied Geophysics 124 (1/2), 3-30.

Saccone, L., Conley, D. J., Koning, E., Sauer, D., Sommer, M., Kaczorek, D., Blecker, S. W., Kelly, E. F., 2007. Assessing the extraction and quantification of amorphous silica in soils of forest and grassland ecosystems. European Journal of Soil Science 58, 1446-1459.

Saffer, D., Marone, C., 2003. Comparison of smectite- and illite-rich gouge frictional properties: application to the updip limit of the seismogenic zone along subduction megathrusts. Earth and Planetary Science Letters 6793, 1-17.

Sagy, A., Reches, Z., Roman, I., 2001. Dynamic fracturing: field and experimental observations. Journal of Structural Geology 23, 1223-1239.

Sagy, A., Reches, Z. E., Fineberg, J., 2002. Dynamic fracture by large extraterrestrial impacts as the origin of shatter cones. Nature 418, 310-313. 
Sakaguchi, A., Chester, F., Curewitz, D., Fabbri, O., Goldsby, D., Kimura, G., Li, C.-F., Masaki, Y., Screaton, E. J., Tsutsumi, A., Ujiie, K., Yamaguchi, A., 2011. Seismic slip propagation to the updip end of plate boundary subduction interface faults: Vitrinite reflectance geothermometry on Integrated Ocean Drilling Program NanTro SEIZE cores. Geology 39, 395-398, doi: 10.1130/G31642.1.

Sammis, C. G., Osborne, R. H., Anderson, J. L., Banerdt, M., White, P., 1986. Self-similar cataclasis in the formation of fault gouge. Pageoph 124 (1/2), 53-78.

Samudrala, O., Huang, Y., Rosakis, A., 2002. Subsonic and Intersonic Shear Rupture of Weak Planes with a Velocity Weakening Cohesive Zone. Journal of Geophysical Research 107.

Savage, H. M., Polissar, P. J., Sheppard, R., Rowe, C. D., Brodsky, E. E., 2014. Biomarkers heat up during earthquakes: New evidence of seismic slip in the rock record. Geology 42 (2), 99-102.

Sawai, M., Niemeijer, A., Plümped, O., Hirose, T., Spiers, C., 2014. Frictional properties of glaucophane schist under hypocentral depth conditions. Asia Oceania Geosciences Society Meeting Abstracts, SE20-D5-AM1-HH-032.

Schleicher, A., van der Pluijm, B., Warr, L., 2012. Chlorite-smectite clay minerals and fault behavior: New evidence from the San Andreas Fault Observatory at Depth (SAFOD) core. Lithosphere 4 (3), 209-220.

Schleicher, A. M., Boles, A., van der Pluijm, B. A., accepted. Response of natural smectite to seimsogenic heating and implications for the 2011 Tohoku earthquake in the japan trench. Geology TBD (TBD), TBD.

Scholz, C. H., 2002. The mechanics of earthquakes and faulting. Cambridge University Press.

Scholz, C. H., Aviles, C., 1986. The fractal geometry of faults and faulting. Earthquake Source Mechanics, 147-155.

Schulz, S. E., Evans, J. P., 1998. Spatial variability in microscopic deformation and composition of the Punchbowl fault, southern California: Implications for mechanisms, fluid-rock interaction, and fault morphology. Tectonophysics 295, $223-244$.

Schulz, S. E., Evans, J. P., 2000. Mesoscopic structure of the Punchbowl Fault, Southern California and the geologic and geophysical structure of active strikeslip faults. Journal of Structural Geology 22, 913-930.

Schwartz, S. Y., Rokosky, J. M., 2007. Slow slip events and seismic tremor at circum-Pacific subduction zones. Reviews of Geophysics 45 (RG3004), 32, doi:10.1029/2006RG000208. 
Segall, P., Pollard, D. D., 1983. Nucleation and growth of strike slip faults in granite. Journal of Geophysical Research 88 (B1), 555-568.

Shaw, C. A., Allen, J. L., 2007. Field rheology and structural evolution of the Homestake shear zone, Colorado. Rocky Mountain Geology 42 (1), 31-56.

Sheppard, R., Polissar, P., Savage, H. M., 2015. Organic thermal maturity as a proxy for frictional fault heating: experimental constraints on methylphenanthrene kinetics at earthquake timescales. Geochemica et Cosmica Acta 151, 103116.

Sherry, T. J., 2014. Earthquakes at stressed ramps emplace injectites. Master's thesis, McGill University.

Sherry, T. J., Rowe, C. D., Kirkpatrick, J. D., Brodsky, E. E., 2012. Emplacement and dewatering of the world's largest exposed sand injectite complex. Geochemistry Geophysics Geosystems 13 (1), doi: 10.1029/2012GC004157.

Sibson, R. H., 1973. Interactions between temperature and pore-fluid pressure during earthquake faulting and a mechanism for partial or total stress relief. Nature $243,66-68$.

Sibson, R. H., 1975. Generation of pseudotachylyte by ancient seismic faulting. The Geophysical Journal of the Royal Astronomical Society 43 (3), 775-794.

Sibson, R. H., 1977. Fault rocks and fault mechanisms. Journal of the Geological Society of London 133, 191-213.

Sibson, R. H., 1982. Fault zone models, heat flow, and the depth distribution of earthquakes in the continental crust of the United States. Bulletin of the Seismological Society of America 72 (1), 151-163.

Sibson, R. H., 1986. Brecciation processes in fault zones: Inferences from earthquake rupturing. Pure and Applied Geophysics 124 (1/2), 159-175.

Sibson, R. H., 1989. Earthquake faulting as a structural process. Journal of Structural Geology $11(1 / 2), 1-14$.

Sibson, R. H., Toy, V. G., 2006. The habitat of fault-generated pseudotachylyte: Presence vs. absence of friction-melt. In: Abercrombie, R., McGarr, A., Kanamori, H., Di Toro, G. (Eds.), Earthquakes: Radiated Energy and the Physics of Faulting: Geophysical Monograph 170. American Geophysical Union, pp. 153-166.

Siman-Tov, S., Aharonov, E., Sagy, A., Emmanuel, S., 2013. Nanograins form carbonate fault mirrors. Geology 41 (6), 703-706. 
Smith, S. A. F., Billi, A., ii Toro, G., Spiess, R., 2011. Principal slip zones in limestone: microstructural characterization and implications for the seismic cycle (Tre Monti fault, central Appenines, Italy. Pure and Applied Geophysics 168 (12), 2365-2393, doi:10.1007/s00024-011-0267-5.

Smith, S. A. F., Bistacchi, A., Mitchell, T. M., Mittempergher, S., Di Toro, G., 2013a. The structure of an exhumed intraplate seismogenic fault in crystalline basement. Tectonophysics 599, 29-44.

Smith, S. A. F., Collettini, C., Holdsworth, R. E., 2008. Recognizing the seismic cycle in ancient faults: CO2-induced fluidization of breccias in the footwall of a sealing low-angle normal fault. Journal of Structural Geology 30, 1034-1046.

Smith, S. A. F., Di Toro, G., Kim, J.-H., Nielsen, S., Billi, A., Speiss, R., 2013b. Coseismic recrystallization during shallow earthquake slip. Geology 41 (1), 63-66.

Solum, J. G., van der Pluijm, B. A., Peacor, D. R., 2003. Influence of phyllosilicate mineral assemblages, fabrics, and fluids on the behavior of the Punchbowl fault, southern California. Journal of Geophysical Research 108 (B52233).

Sone, H., Shimamoto, T., 2009. Frictional resistance of faults during accelerating and decelerating earthquake slip. Nature Geoscience 2 (10), 705-708.

Spray, J. G., 2005. Evidence for melt lubrication during large earthquakes. Geophysical Research Letters 32 (L07301).

Spray, J. G., 2010. Frictional melting processes in planetary materials: from hypervelocity impacts to earthquakes. Annual Review of Earth and Planetary Sciences 38, 221-254, doi: 10.1146/annurev.earth.031208.100045.

Stewart, R., Reimold, W., Charlesworth, E., Ortlepp, W., 2001. The nature of a deformation zone and fault rock related to a recent rockburst at western deep levels gold mine, witwatersrand basin, south africa. Tectonophysics 337 (3), 173190 .

Stünitz, H., Keulen, N., Hirose, T., Heilbronner, R., 2010. Grain size distribution and microstructures of experimentally sheared granitoid gouge at coseismic slip rates-criteria to distinguish seismic and aseismic faults? Journal of Structural Geology 32 (1), 59-69.

Suchy, V., Frey, M., Wolf, M., 1997. Vitrinite reflectance and shear-induced graphitization in orogenic belts: A case study from the Kandersteg area, Helvetic Alps, Switzerland. International Journal of Coal Geology 34, 1-20.

Sulem, J., Famin, V., 2009. Thermal decomposition of carbonates in fault zones: Slip-weakening and temperature-limiting effects. Journal of Geophysical Research 114 (B03309), doi: 10.1029/2008JB006004. 
Sulem, J., Lazar, P., Vardoulakis, I., 2007. Thermo-poro-mechanical properties of clayey gouge and application to rapid fault shearing. International journal for numerical and analytical methods in geomechanics 31 (3), 523-540.

Sulem, J., Vardoulakis, I., Ouffroukh, H., Boulon, M., Hans, J., 2004. Experimental characterization of the thermo-poro-mechanical properties of the Aegion Fault gouge. Comptes Rendus Geoscience 336, 455-466.

Swanson, E. M., Wernicke, B. P., Eiler, J. M., Losh, S., 2012. Temperatures and fluids on faults based on carbonate clumped-isotope thermometry. American Journal of Science 312 (1), 1-21.

Swanson, M. T., 2005. Geometry and kinematics of adhesive wear in brittle strikeslip fault zones. Journal of Structural Geology 27 (5), 871-887.

Swanson, M. T., 2006a. Late Paleozoic strike-slip faults and related vein arrays of Cape Elizabeth, Maine. Journal of Structural Geology 28, 456-473.

Swanson, M. T., 2006b. Pseudotachylyte-bearing strike-slip faults in mylonitic host rocks, Fort Foster Brittle Zone, Kittery, Maine. In: Abercrombie, R., McGarr, A. M., Di Toro, G., Kanamori, H. (Eds.), Earthquakes: Radiated Energy and the Physics of Faulting. Vol. 170. American Geophysical Union, pp. 167-179.

Sweeney, J. J., Burnham, A. K., 1990. Evaluation of a simple model of vitrinite reflectance based on chemical kinetics. AAPG Bulletin 74 (10), 1559-1570.

Teichmüller, M., Teichmüller, R., 1979. Diagenesis of coal (coalification). Diagenesis in Sediments and Sedimentary Rocks, Elsevier, Amsterdam, 207-246.

Tembe, S., Lockner, D., fong Wong, T., 2009. Constraints on the stress state of the San Andreas Fault with analysis based on core and cuttings from San Andreas Fault Observatory at Depth (SAFOD) drilling phases 1 and 2. Journal of Geophysical Research 114 (B11401), doi: 10.1029/2008JB005883.

Tesei, T., Collettini, C., Carpenter, B. M., Viti, C., Marone, C., 2012. Frictional strength and healing behavior of phyllosilicate-rich faults. Journal of Geophysical Research: Solid Earth (1978-2012) 117 (B9).

Tisato, N., Di Toro, G., De Rossi, N., Quaresimin, M., Candela, T., 2012. Experimental investigation of flash weakening in limestone. Journal of Structural Geology 38, 183-199.

Trepmann, C. A., Spray, J. G., 2005. Planar microstructures and dauphiné twins in shocked quartz from the charlevoix impact structure, canada. Geological Society of America Special Papers 384, 315-328.

Trepmann, C. A., Stöckhert, B., 2003. Quartz microstructures developed during non-steady state plastic flow at rapidly decaying stress and strain rate. Journal of Structural Geology 25 (12), 2035-2051. 
Tschegg, C., Grasemann, B., 2009. Deformation and alteration of a granodiorite during low-angle normal faulting (Serifos, Greece. Lithosphere 1 (3), 139-154.

Tullis, J., 1970. Quartz: preferred orientation in rocks produced by dauphiné twinning. Science 168 (3937), 1342-1344.

Ujiie, K., Kameyama, M., Yamaguchi, A., 2010. Geological record of thermal pressurization and earthquake instability of subduction thrusts. Tectonophysics 485 , 260-268.

Ujiie, K., Tsutsumi, A., Kameda, J., 2011. Reproduction of thermal pressurization and fluidization of clay-rich fault gouges by high-velocity friction experiments and implications for seismic slip in natural faults. In: Fagereng, r., Toy, V. G., Rowland, J. V. (Eds.), Geology of the Earthquake Source: A Volume in Honour of Rick Sibson. Vol. 359. Geological Society, London, Special Publications, pp. $267-285$.

Ujiie, K., Yamaguchi, A., Taguchi, S., 2008. Stretching of fluid inclusions in calcite as an indicator of frictional heating on faults. Geology 36 (2), 111-114.

Ujiie, K., Yamaguchi, H., Sakaguchi, A., Toh, S., 2007. Pseudotachylytes in an ancient accretionary complex and implications for melt lubrication during subduction zone earthquakes. Journal of Structural Geology 29, 599-613.

van der Elst, N., Brodsky, E. E., Le Bas, P. Y., Johnson, P. A., 2012. Autoacoustic compaction in steady shear flows: Experimental evidence for suppression of shear dilatancy by internal acoustic vibration. Journal of Geophysical Research 117 (B9).

Verberne, B. A., de Bresser, J. H. P., Niemeijer, A. R., Spiers, C. J., de Winter, D. A. M., Plümper, O., 2013. Nanocrystalline slip zones in calcite fault gouge show intense crystallographic preferred orientation: Crystal plasticity at sub-seismic slip rates at $18-150^{\circ} \mathrm{c}$. Geology 41 (8), 863-866.

Verberne, B. A., He, C., Spiers, C. J., 2010. Frictional properties of sedimentary rocks and natural fault gouge from the longmen shan fault zone, sichuan, china. Bulletin of the Seismological Society of America 100 (5B), 2767-2790.

Verberne, B. A., Plümped, O., de Winter, D. A. M., Spiers, C. J., 2014. Superplastic nanofibrous slip zones control seismogenic fault friction. Science 346.

Vernooij, M. C. G., Langenhorst, F., 2005. Experimental reproduction of tectonic deformation lamellae in quartz and comparison to shock-induced planar deformation features. Meteoritics \& Planetary Science 40 (9/10), 1353-1361.

Viola, G., Mancktelow, N. S., Miller, J. A., 2006. Cyclic frictional-viscous slip oscillations along the base of an advancing nappe complex: Insights into brittleductile nappe emplacement mechanisms from the Naukluft Nappe Complex, central Namibia. Tectonics 25, doi: 10.1029/2005TC001939. 
Wakabayashi, J., Rowe, C. D., 2015. Whither the megathrust? localization of largescale subduction slip along the contact of a mélange. International Geophysical Journal 57 (5-8), 854-870.

Wallace, L. M., Beavan, J., 2006. A large slow slip event on the central Hikurangi subduction interface beneath the Manawatu region, North Island, New Zealand. Geophysical Research Letters 33 (L11301).

Warr, L. N., Cox, S., 2001. Clay mineral transformations and weakening mechanisms along the Alpine Fault, New Zealand. In: Holdsworth, R. E., Strachan, R. A., Magloughlin, J. F., Knipe, R. J. (Eds.), The Nature and Tectonic Significance of Fault Zone Weakening. Vol. 186. Geological Society of London, Special Publications, pp. 85-101.

Wech, A. G., Bartlow, N. M., 2014. Slip rate and tremor genesis in Cascadia. Geophysical Research Letters 41, 7.

Wechsler, N., Allen, E. E., Rockwell, T. K., Girty, G., Chester, J. S., Ben-Zion, Y., 2011. Characterization of pulverized granitoids in a shallow core along the san andreas fault, littlerock, ca. Geophysical Journal International 186 (2), 401-417.

Wenk, H. R., 1978. Are pseudotachylites products of fracture or fusion? Geology $6,507-511$.

Wenk, H.-R., Janssen, C., Kenkmann, T., Dresen, G., 2011. Mechanical twinning in quartz: Shock experiments, impact, pseudotachylytes and fault breccias. Tectonophyiscs 510, 69-79.

Wenk, H.-R., Kanitpanyacharoen, W., Voltolini, M., 2010. Preferred orientation of phyllosilicates: Comparison of fault gouge, shale and schist. Journal of structural geology 32 (4), 478-489.

Wenk, H.-R., Lonardelli, I., Vogel, S., Tullis, J., 2005. Dauphiné twinning as evidence for an impact origin of preferred orientation in quartzite: an example from Vredefort, South Africa. Geology 33 (4), 273-276.

White, J., Hadizadeh, J., Kennedy, L. A., 2013. Structured amorphization in gouge seismic or aseismic slip? Geological Society of America Abstracts 45.

White, J. C., 2012. Paradoxical pseudotachylyte - fault melt outside the seismogenic zone. Journal of Structural Geology 38, 11-20.

White, J. C., Hadizadeh, J., Tullis, T. E., Goldsby, D. L., 2009. Mechanical amoprhization during experimental shearing of synthetic granite gouge. Geophysical Research Abstracts 11 (EGU2009-8996).

Wilks, K. R., Mastelerz, M., Bustin, R. M., Ross, J. V., 1993. The role of shear strain in the graphitization of a high-volatile bituminous and an anthracitic coal. International Journal of Coal Geology 22, 247-277. 
Willemse, E. J. M., Pollard, D. D., 1998. On the orientation and patterns of wing cracks and solution surfaces at the tips of a sliding flaw or fault. Journal of Geophysical Research 103 (B2), 2427-2438.

Wilson, B., Dewers, T., Reches, Z., Brune, J., 2005. Particle size and energetics of gouge from earthquake rupture zones. Nature 434, 749-752.

Wilson, J. E., Chester, J. S., Chester, F. M., 2003. Microfracture analysis of fault growth and wear processes, Punchbowl Fault, San Andreas system, California. Journal of Structural Geology 25, 1855-1873.

Xia, K., Nasseri, M., Mohanty, B., Lu, F., Chen, R., Luo, S., 2008. Effects of microstructures on dynamic compression of barre granite. International Journal of Rock Mechanics and Mining Sciences 45 (6), 879-887.

Xu, X., Yu, G., Ma, W., Klinger, Y., Tapponnier, P., Woerd, V. D., 2006. Reevaluation of surface rupture parameters and faulting segmentation of the 2001 kunlunshan earthquake (mw7.8). Journal of Geophysical Research 111.

Yamaguchi, A., Cox, S. F., Kimura, G., Okamoto, S., 2011a. Dynamic changes in fluid redox state associated with episodic fault rupture along a megasplay fault in a subduction zone. Earth and Planetary Science Letters 302, 369-377.

Yamaguchi, A., Ishikawa, T., Kato, Y., Nozaki, T., Meneghini, F., Rowe, C. D., Moore, J. C., Tsutsumi, A., Kimura, G., 2014. Fluid-rock interaction recorded in black fault rocks in the Kodiak accretionary complex, Alaska. Earth, Planets and Space 66 (58).

Yamaguchi, A., Sakaguchi, A., Sakamoto, T., Iijima, K., Kameda, J., Kimura, G., Ujiie, K., Chester, F. M., Fabbri, O., Goldsby, D., et al., 2011b. Progressive illitization in fault gouge caused by seismic slip propagation along a megasplay fault in the nankai trough. Geology 39 (11), 995-998.

Yasuda, N., Sumita, I., 2014. Shaking conditions required for flame structure formation in a water-immersed granular medium. Progress in Earth and Planetary Science 1 (13), 11.

Yuan, F., Prakash, V., 2008. Slip weakening in rocks and analog materials at coseismic slip rates. Journal of the Mechanics and Physics of Solids 56 (2), 542-560.

Yuan, F., Prakash, V., Tullis, T., 2011. Origin of pulverized rocks during earthquake fault rupture. Journal of Geophysical Research 116 (B6).

Yund, R., Blanpied, M., Tullis, T., Weeks, J., 1990. Amorphous material in high strain experimental fault gouges. Journal of Geophysical Research 95 (B10), $15589-15$. 